\title{
SCIENTIFIC REPORTS

\section{Evaluation of Tellurium as a Fuel Additive in Neodymium-Containing U-Zr Metallic Fuel}

\begin{abstract}
Nathan D. Jerred ${ }^{1,2}$, Rabi Khanal ${ }^{1}$, MichaelT. Benson ${ }^{2}$, Emmanuel Perez ${ }^{2}$, James A. King ${ }^{2}$, Megha Dubey ${ }^{3}$, Jatuporn Burns ${ }^{3}$, Indrajit Charit ${ }^{1 *}$, Samrat Choudhury ${ }^{1}$ \& Robert D. Mariani ${ }^{4}$

Phase-stability in a U-Zr-Te-Nd multi-component metallic fuel for advanced nuclear reactors is systematically investigated by taking into account binary, ternary and quaternary interactions between elements involved. Historically, the onset of fuel-cladding chemical interactions $(\mathrm{FCCl})$ greatly limits the burnup potential of $U$-Zr fuels primarily due to interactions between lanthanide fission products and cladding constituents. Tellurium (Te) is evaluated as a potential additive for U-Zr fuels to bind with lanthanide fission products, e.g. neodymium (Nd), negating or mitigating the $\mathrm{FCCl}$ effect. Potential fresh fuel alloy compositions with the Te additive, U-Zr-Te, are characterized. Te is found to completely bind with $\mathrm{Zr}$ within the $\mathrm{U}-\mathrm{Zr}$ matrix. Alloys simulating the formation of the lanthanide element $\mathrm{Nd}$ within U-Zr-Te are also evaluated, where the Te-Nd binary interaction dominates and $\mathrm{NdTe}$ is found to form as a high temperature stable compound. The experimental observations agree well with the trends obtained from density functional theory calculations. According to the calculated enthalpy of mixing, $\mathrm{Zr}$-Te compound formation is favored in the U-Zr-Te alloy whereas NdTe compound formation is favored in the U-Zr-Te-Nd alloy. Further, the calculated charge density distribution and density of states provide sound understanding of the mutual chemical interactions between elements and phase-stability within the multi-component fuel.
\end{abstract}

Phase stability in a multi-component alloy is determined by a complex set of mutual chemical, elastic and other energetic interactions between elements of the alloy. Such binary, ternary, and quaternary interactions between two or more elements lead to the minimization of the total energy of the alloy. Understanding such interactions is critical to the design of alloy chemistry for a targeted application. In this study, experimental and theoretical efforts are combined to understand such mutual interactions between elements to investigate the overall phase stability in a U-Zr-Te-Nd multi-component alloy. The binary U-Zr metallic nuclear fuels have largely been used in fast-spectrum reactors, such as the Experimental Breeder Reactor II (EBR-II), and they continue to be attractive for advanced nuclear reactor concepts, such as the advanced sodium-cooled fast reactor (SFR). Some major advantages of such fuel systems are their ease of fabrication and reprocessing, high thermal conductivity, good compatibility with the sodium coolant, and their ability to contain high densities of fissile and fertile materials ${ }^{1-3}$. However, the onset of chemical interactions between fission products and fuel components with cladding constituents greatly limits the burnup potential of $U-Z r$ fuels.

The lanthanide elements have been found to be a major cause of chemical interactions at the fuel-cladding interface, also known as fuel-cladding chemical interaction (FCCI). Such lanthanides form in the fuel as fission products and tend to migrate to the fuel periphery; being primarily driven by temperature gradients via 'liquid-like' transport ${ }^{4-6}$. Metallic fuels tend to swell due to fission gas formations within the first $1-2$ at.\% burnup leading to intimate contact to be made between the fuel and cladding components ${ }^{2,7}$. With prolonged reactor operation, such fuel - cladding contact leads to the initiation of FCCI. Lanthanide elements (Nd, Ce, $\mathrm{La}$ and $\mathrm{Pr}$ ), being primarily immiscible in the U-Zr system, along with fuel constituents tend to interact with cladding constituents at the fuel - cladding interface. Such interactions can lead to the formation of brittle, low-melting phases exacerbating cladding wastage, which can eventually lead to cladding breach ${ }^{4}$. Therefore, to increase metallic fuel longevity and achieve greater fuel burnups, an effective method to mitigate FCCI is needed.

${ }^{1}$ Department of Chemical and Materials Engineering, University of Idaho, Moscow, Idaho, 83844, USA. ${ }^{2}$ Materials and Fuels Complex Division, Idaho National Laboratory, Idaho Falls, Idaho, 83415, USA. ${ }^{3}$ Microscopy and Characterization Suite, Center for Advanced Energy Studies, Idaho Falls, Idaho, 83401, USA. ${ }^{4}$ Nuclear Science and Technology Division, Idaho National Laboratory, Idaho Falls, Idaho, 83415, USA. *email: icharit@uidaho.edu 


\begin{tabular}{|l|l|l|}
\hline Alloy & Composition in wt.\% & Composition in at.\% \\
\hline $2 \mathrm{Te}$ & $\mathrm{U}-10 \mathrm{Zr}-2 \mathrm{Te}$ & $\mathrm{U}-22.2 \mathrm{Zr}-3.17 \mathrm{Te}$ \\
\hline $4 \mathrm{Te}$ & $\mathrm{U}-10 \mathrm{Zr}-4 \mathrm{Te}$ & $\mathrm{U}-21.8 \mathrm{Zr}-6.24 \mathrm{Te}$ \\
\hline $2 \mathrm{Te}-2 \mathrm{Nd}$ & $\mathrm{U}-10 \mathrm{Zr}-2.16 \mathrm{Te}-2 \mathrm{Nd}$ & $\mathrm{U}-21.9 \mathrm{Zr}-3.4 \mathrm{Te}-2.8 \mathrm{Nd}$ \\
\hline $4 \mathrm{Te}-4 \mathrm{Nd}$ & $\mathrm{U}-10 \mathrm{Zr}-4.3 \mathrm{Te}-4 \mathrm{Nd}$ & $\mathrm{U}-21.3 \mathrm{Zr}-6.6 \mathrm{Te}-5.4 \mathrm{Nd}$ \\
\hline
\end{tabular}

Table 1. Alloys evaluated in this study.

Several methods have been proposed to control FCCI, including internal cladding liners ${ }^{8}$, internal cladding coatings $^{9}$ and fuel additives ${ }^{6}$. As opposed to acting as a diffusion barrier, i.e. liners and coatings, fuel additives are alloyed with the fuel to form high-temperature, stable compounds with lanthanide fission products as they form within the fuel during irradiation, stabilizing them within the fuel meat and limiting their interaction with cladding constituents at the fuel - cladding interface. Criteria for potential additives have previously been developed by Mariani et al. ${ }^{6}$, several of which have been studied $-\mathrm{Pd}^{6,10}, \mathrm{Sn}^{11}, \mathrm{Sb}^{12,13}, \mathrm{Sn}+\mathrm{Sb}^{14}$, and $\mathrm{In}^{13,15}$, and have demonstrated additives as a promising approach to counter FCCI. Additionally, As and Se have been identified as potential additives based on density functional theory (DFT) calculations and experimental observations ${ }^{16}$.

Tellurium (Te) was initially identified as a potential additive for metallic nuclear fuels by Mariani et al. ${ }^{6}$ but detailed experimental work has been limited in this area. The focus of the present study is an evaluation of Te's effectiveness to bind with neodymium (Nd). First principles studies carried out by Khanal et al. ${ }^{16}$ show agreement in the potential of Te to bind with $\mathrm{Nd}$ in an $\alpha-\mathrm{U}$ matrix. Recent research conducted by Xie et al. ${ }^{17}$ characterized the interactions of Te with another lanthanide element, cerium (Ce), in a U-10Zr alloy. In their evaluation of the $\mathrm{U}-10 \mathrm{Zr}$-Te alloy, they were unable to obtain direct evidence of the formation of a $\mathrm{Zr}$-Te phase; instead they postulated the formation of a Te-Zr-U ternary phase. Interestingly, the current research confirms the formation of a non-equilibrium phase $\mathrm{Zr}_{2} \mathrm{Te}$ in a similar alloy composition. Furthermore, it is worth noting that in their characterization of the U-10Zr-Te-Ce alloy, their results indicate Te and Ce primarily form the stable compound CeTe.

In the present study, the microstructure of potential fuel compositions that may be resistant to FCCI are characterized, followed by a characterization of fuel compositions that contain $\mathrm{Nd}$ to simulate the formation of lanthanide fission products through fuel burnup. $\mathrm{Nd}$ was chosen for this study due to its identification as a predominant lanthanide to form within $\mathrm{U}-10 \mathrm{Zr}$ fuel irradiated in a liquid breeder fast reactor EBR-II ${ }^{6}$ and has been observed to readily diffuse into the cladding ${ }^{4}$. Furthermore, this research focuses on the mutual interactions between elements in the U-Zr-Te and U-Zr-Te-Nd multi-component alloys, which lead to stable phase formations within the $\mathrm{U}-\mathrm{Zr}$ matrix.

\section{Results and Discussion}

Four alloys evaluated in the current work are listed in Table 1. The $2 \mathrm{Te}$ and $4 \mathrm{Te}$ alloys represent potential fresh $\mathrm{U}-\mathrm{Zr}$ fuels containing $\mathrm{Te}$ as an additive. The $2 \mathrm{Te}-2 \mathrm{Nd}$ and $4 \mathrm{Te}-4 \mathrm{Nd}$ alloys represent simplified fuel compositions that simulate the formation of lanthanide fission products within the fuel through irradiation, where Nd represents the lanthanide fission product. The Te addition is based on the anticipated amount needed to bind all of the lanthanides that form in the fuel at the respective concentrations. The concentration of neodymium in the alloys represents the anticipated total lanthanide amount to form within the fuel at both 8 and 16 at.\% burnups based on fission product concentrations reported by Mariani et al. ${ }^{6}$. Essentially, the additive - lanthanide atomic ratio is targeted to be 1:1; however, the alloys are in essence slightly additive-rich to counter possible volatilization loss of tellurium during casting.

During initial arc-melting and subsequent drop casting of the alloys, some loss of Te was observed. Tellurium is considered a metalloid and has a relatively low melting temperature of $723 \mathrm{~K}\left(450^{\circ} \mathrm{C}\right)$ and boiling point of $1263 \mathrm{~K}\left(990^{\circ} \mathrm{C}\right)$, which leads to a narrow temperature range where the element can remain in a liquid state. Loss of Te primarily occurred during its addition to the U-10Zr (wt.\%) button, which requires an increased amount of energy to fully liquefy having a solidus temperature of approximately $1521 \mathrm{~K}\left(1248^{\circ} \mathrm{C}\right)$ and liquidus temperature between $1628 \mathrm{~K}-1633 \mathrm{~K}\left(1355^{\circ} \mathrm{C}-1360^{\circ} \mathrm{C}\right)^{18}$. Once Te was homogenized into the U-10Zr (wt.\%) alloy, it became stabilized by the formation of $\mathrm{Zr}$-Te precipitates (further discussed in later sections).

Microstructural and compositional analysis of $\mathrm{U}-10 \mathrm{Zr}$ with Te additive. The microstructures of the $2 \mathrm{Te}$ and $4 \mathrm{Te}$ alloys are shown in the scanning electron microscopy (SEM) backscatter electron (BSE) images in Fig. 1. Round grey-contrast precipitates are observed within the matrix of both alloys ranging in size from sub-micron to approximately $20 \mu \mathrm{m}$ across. It should be noted that the matrix, a combination of a primary light phase with a dispersed light-grey phase, is the expected phase formation of the U-Zr system in the as-cast condition. Extensive work has been done on U-Zr alloys, and in particular the U-10Zr (wt.\% ${ }^{18-24}$. Furthermore, the phase formations between $\mathrm{U}$ and $\mathrm{Zr}$ in the as-cast condition, specifically the co-formation of the $\alpha-\mathrm{U}$ and $\delta$ - $\mathrm{UZr}_{2}$ phases, have been discussed elsewhere ${ }^{19,23}$. A more recent study by Irukuvarghula et al. ${ }^{24}$ concluded the phase formations for the majority of $\mathrm{U}-\mathrm{Zr}$ alloys, including the $\mathrm{U}-10 \mathrm{Zr}$ alloy, in the as-cast condition are likely $\alpha$ - $\mathrm{U}$ phase and a disordered, metastable $\omega$ phase. Even though the $\omega$ and $\delta$ phases have the same chemical composition, the $\delta$ phase is partially ordered. Given the extensive knowledge base on the $\mathrm{U}-\mathrm{Zr}$ binary system, the present study focuses on the observed ternary interactions of Te, $\mathrm{U}$, and $\mathrm{Zr}$ and how the addition of $\mathrm{Nd}$ changes such mutual interactions.

Elemental maps of $\mathrm{U}, \mathrm{Zr}$ and $\mathrm{Te}$, as obtained from energy dispersive X-ray spectroscopy (EDS) studies of the 2Te alloy for the location displayed in Fig. 1(a1), are shown in Fig. 2. The maps reveal that the precipitates are the 


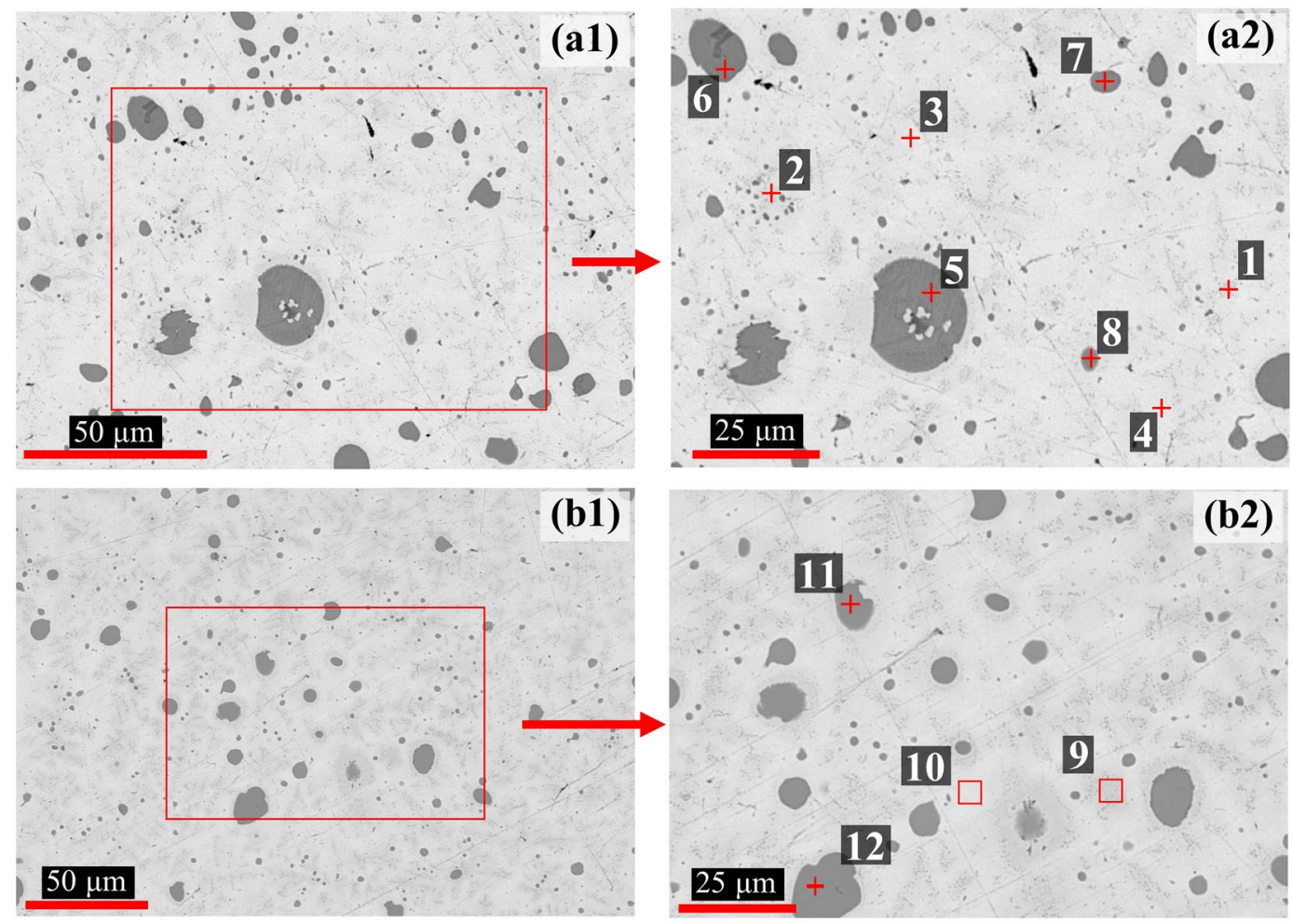

Figure 1. BSE SEM images of (a1) the 2Te alloy and (b1) the 4Te alloy; (a2,b2) are the magnified BSE SEM images of the 'red' rectangular inset regions in (a1) and (b1), respectively.

combination of $\mathrm{Zr}$ and Te contained within a primarily $\mathrm{U}$ matrix. Elemental compositions of areas designated in Fig. 1(a2,b2) are listed in Table 2. Based on EDS point analysis, the precipitates (points $5-8,11,12$ ) exhibit a ratio range of 2:1 to 2.4:1 ( $\mathrm{Zr}$ :Te), indicating that they are likely the $\mathrm{Zr}_{2} \mathrm{Te}$ compound. Small white inclusions are also detected in the larger spherical precipitates (Fig. 1(a1)). Such inclusions are likely trapped matrix material. Xie et al. also made similar observations in their analysis of a U-10Zr-Te alloy ${ }^{17}$.

Focused X-ray diffraction (XRD) analyses of alloys 2 Te and 4 Te alloys are presented in the form of XRD patterns in Fig. 3, and the corresponding crystallographic information listed in Table 3. The XRD pattern shows that the alloys are primarily comprised of the $\alpha$-U based solid solution phase. The presence of $\mathrm{UO}_{2}$ was also seen and its formation is likely due to the specimen exposure to air during analysis. $\mathrm{The} \mathrm{Zr}_{2} \mathrm{Te}$ compound was also detected confirming the EDS elemental data obtained on the precipitates in the alloy. The $\mathrm{Zr}_{2} \mathrm{Te}$ phase is not depicted as an equilibrium phase on the $\mathrm{Zr}$-Te binary phase diagram by Okamoto ${ }^{25}$. However, more recent work by Örlygsson and Harbrecht ${ }^{26}$ detailed the existence of the $\mathrm{Zr}_{2} \mathrm{Te}$ phase. Their study detected the $\mathrm{Zr}_{2} \mathrm{Te}$ phase in an as-cast specimen using EDS analysis and powder-based XRD. Further, they suggested that the $\mathrm{Zr}_{2} \mathrm{Te}$ phase is formed through a peritectic reaction near the incongruent melting point of the $\mathrm{Zr}_{3}$ Te phase. It is plausible that $\mathrm{Zr}_{2} \mathrm{Te}$ is a metastable phase, which may decompose to stable $\mathrm{Zr}_{5} \mathrm{Te}_{4}$ and $\mathrm{Zr}_{3} \mathrm{Te}$ compounds ${ }^{25}$.

In analyzing U-10Zr-Te alloys, it is important to note that no free Te was observed within the alloys; instead it is clear that Te is primarily binding with $\mathrm{Zr}$ to form precipitates. Similar observations have been made in other additives-based research in U-10Zr matrix ${ }^{11,12,15,17}$. Such Zr-Te phase formation is deemed beneficial as they would stabilize the additive within the fresh fuel alloy. Here the precipitates were found to primarily consist of the $\mathrm{Zr}_{2}$ Te phase, which implies that the fuel composition, i.e. U-10Zr, is not being maintained when Te is added to the fuel. As $\mathrm{Zr}$ is added to increase the solidus temperature of the alloy, the loss of $\mathrm{Zr}$ from the matrix solid solution may decrease the overall solidus temperature of the fuel matrix. To counter such outcome, additional $\mathrm{Zr}$ may be needed to maintain the necessary solidus temperature when additives are employed.

Microstructural and compositional analysis of U-10Zr-2Te-2Nd and U-10Zr-4Te-4Nd alloys. To evaluate the effectiveness of the Te additive to bind with potential lanthanide fission products, Nd was added into the fuel alloys. Here two such alloys listed in Table 1 were evaluated. The Te addition of 2.16 wt.\% and 4.3 wt.\% corresponds to a targeted 1:1 atomic ratio of additive to lanthanide at the respective burnups. It is important to note that $\mathrm{Nd}$ was added to a U-Zr-Te alloy, and therefore the microstructure of the pre-alloy can be presumed to be similar to the previously discussed U-Zr-Te alloys. Therefore, in order for the additive (Te) to bind with the lanthanide $(\mathrm{Nd})$, the $\mathrm{Zr}_{2}$ Te precipitates would need to decompose. As previously mentioned, in casting $\mathrm{Nd}$ into the $\mathrm{U}-\mathrm{Zr}$-Te alloy, the Te is stabilized by the formation of $\mathrm{Zr}_{2} \mathrm{Te}$. Based on the research of Örlygsson and Harbrecht ${ }^{26}$ it can be inferred that $\mathrm{Zr}_{2}$ Te has a melting temperature sufficiently higher than the melting temperature of $\mathrm{Nd}\left(T_{\text {melt }}=1021^{\circ} \mathrm{C}\right)$, therefore loss of Te was not likely when $\mathrm{Nd}$ was added. 

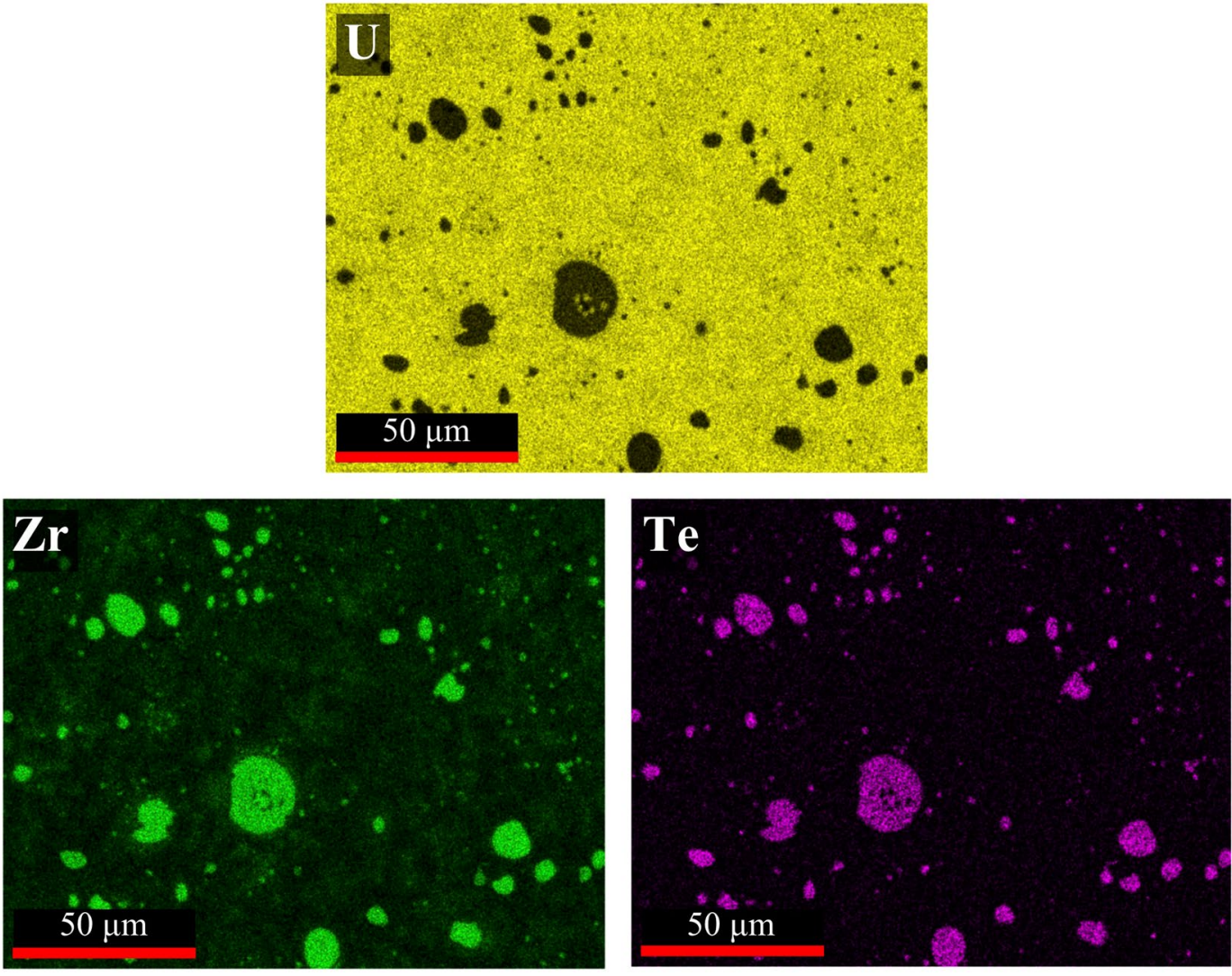

Figure 2. Elemental EDS maps of the 2Te alloy. Analysis location aligns with the area imaged in Fig. 1(a1).

\begin{tabular}{|c|c|c|c|c|c|c|c|c|c|}
\hline & \multicolumn{4}{|c|}{ Fig. 1(a2) } & & \multicolumn{4}{|c|}{ Fig. 1(b2) } \\
\hline & $\mathrm{U}$ & $\mathrm{Zr}$ & $\mathrm{Te}$ & Phase $^{\mathrm{a}}$ & & $\mathrm{U}$ & $\mathrm{Zr}$ & $\mathrm{Te}$ & Phase $^{\mathrm{a}}$ \\
\hline 1 & 62 & 31 & 7 & $\mathrm{U}-\mathrm{Zr}^{\mathrm{b}}$ & 9 & 59 & 40 & 2 & $\mathrm{U}-\mathrm{Zr}^{\mathrm{b}}$ \\
\hline 2 & 60 & 38 & 2 & $\mathrm{U}-\mathrm{Zr}^{\mathrm{b}}$ & 10 & 83 & 16 & 1 & $\mathrm{U}-\mathrm{Zr}^{\mathrm{b}}$ \\
\hline 3 & 84 & 14 & 2 & $\mathrm{U}-\mathrm{Zr}^{\mathrm{b}}$ & 11 & 6 & 67 & 27 & $\mathrm{Zr}_{2} \mathrm{Te}$ \\
\hline 4 & 77 & 21 & 2 & $\mathrm{U}-\mathrm{Zr}^{\mathrm{b}}$ & 12 & 5 & 67 & 28 & $\mathrm{Zr}_{2} \mathrm{Te}$ \\
\hline 5 & 9 & 64 & 27 & $\mathrm{Zr}_{2} \mathrm{Te}$ & & & & & \\
\hline 6 & 6 & 67 & 27 & $\mathrm{Zr}_{2} \mathrm{Te}$ & & & & & \\
\hline 7 & 7 & 62 & 31 & $\mathrm{Zr}_{2} \mathrm{Te}$ & & & & & \\
\hline 8 & 11 & 63 & 26 & $\mathrm{Zr}_{2} \mathrm{Te}$ & & & & & \\
\hline
\end{tabular}

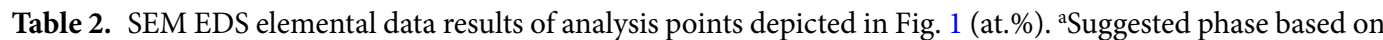
EDS analysis. ${ }^{b}$ Matrix phase of the as-cast $\mathrm{U}-\mathrm{Zr}$ alloy.

Representative optical micrographs of the $2 \mathrm{Te}-2 \mathrm{Nd}$ and $4 \mathrm{Te}-4 \mathrm{Nd}$ alloys are shown in the SEM-BSE images of Fig. 4(a,b), respectively. Both alloys have multiple precipitated phases within the U-Zr matrix. Both show a combination of larger grey-contrast precipitates (approximately $25 \mu \mathrm{m}$ in size) along with various sized, smaller grey-contrast precipitates. Furthermore, dendritic and small, round black precipitates are observed to form throughout the matrix, with instances of the latter precipitates forming around the large grey-contrast precipitates. Both alloys exhibit the light- and light-grey matrix phases of the U-Zr as-cast structure as previously observed in the U-Zr-Te alloys. The primary difference between the two U-Zr-Te-Nd alloys is the presence of small, round black precipitate clusters that have formed within sections of the light-grey matrix in the $4 \mathrm{Te}-4 \mathrm{Nd}$ alloy (Fig. 4(b)).

Elemental EDS maps for the 2Te-2Nd and 4Te-4Nd alloys, which correspond to the locations imaged in Fig. 4, are shown in Figs 5 and 6, respectively. The EDS maps in Fig. 5 show that the larger grey-contrast precipitates observed in the $2 \mathrm{Te}-2 \mathrm{Nd}$ alloy consist of Te and $\mathrm{Nd}$, whereas the small black and grey-contrast precipitates are found to primarily contain $\mathrm{Zr}$ and $\mathrm{Nd}$, respectively. In the $2 \mathrm{Te}-2 \mathrm{Nd}$ alloy, the Te appears to be contained in all of the same precipitates as $\mathrm{Nd}$ and no longer appears to be contained with any $\mathrm{Zr}$-containing precipitates. The EDS maps in Fig. 6 show that the grey-contrast precipitates and the dendritic precipitates observed in the $4 \mathrm{Te}-4 \mathrm{Nd}$ 


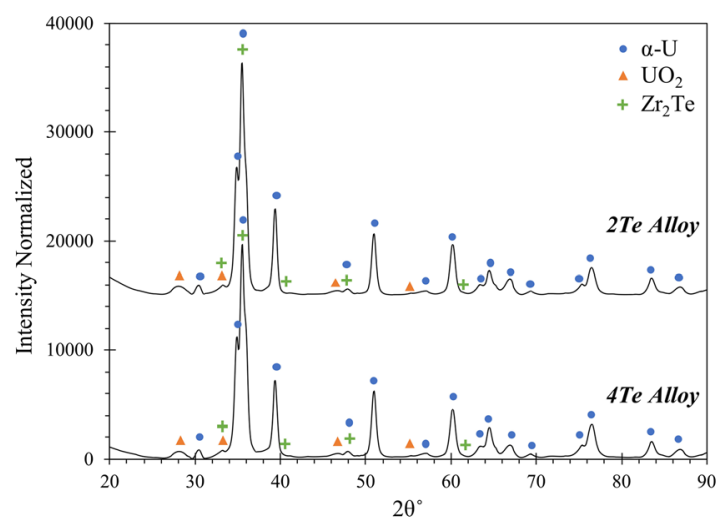

Figure 3. XRD patterns of the $2 \mathrm{Te}$ and $4 \mathrm{Te}$ alloys.
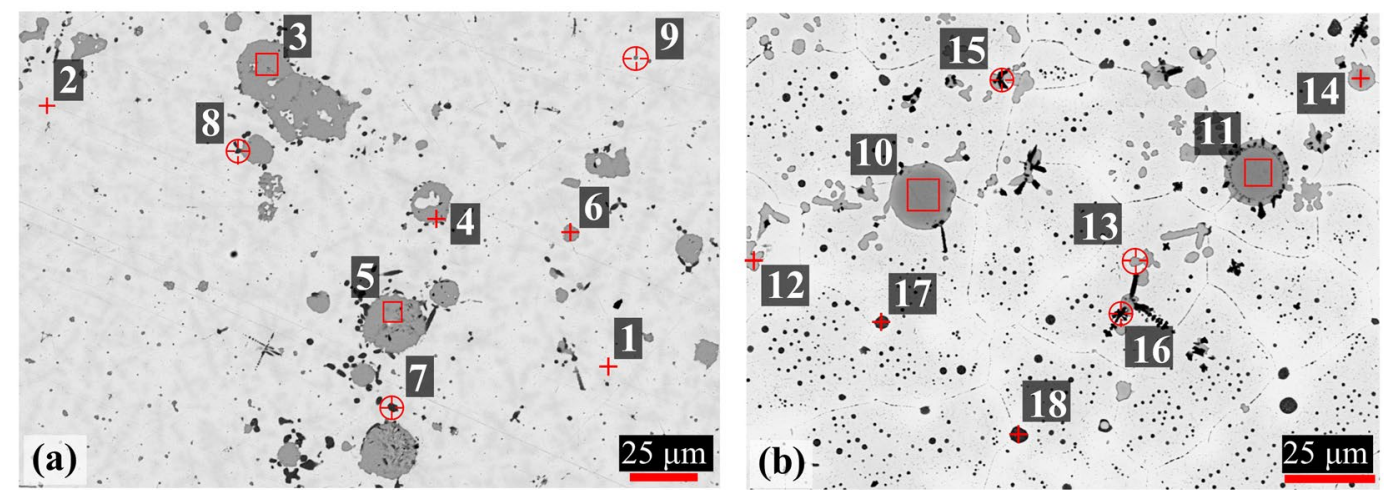

Figure 4. BSE images of (a) the $2 \mathrm{Te}-2 \mathrm{Nd}$ and (b) the $4 \mathrm{Te}-4 \mathrm{Nd}$ alloys.

\begin{tabular}{|c|c|c|c|c|c|c|c|}
\hline \multirow[b]{2}{*}{ Compound } & \multirow{2}{*}{$\begin{array}{l}\text { Pearson } \\
\text { Symbol }\end{array}$} & \multirow[b]{2}{*}{ Space Group } & \multirow[b]{2}{*}{ Cell parameters } & \multicolumn{4}{|c|}{ Alloy ID ${ }^{a}$} \\
\hline & & & & $2 \mathrm{Te}$ & $4 \mathrm{Te}$ & 2Te-2Nd & $4 \mathrm{Te}-4 \mathrm{Nd}$ \\
\hline$\alpha-\mathrm{U}^{31}$ & oS4 & Cmcm (63) & $\begin{array}{l}a=0.286, b=0.585, \\
c=0.498[\mathrm{~nm}] \\
\alpha=\beta=\gamma=90^{\circ}\end{array}$ & $\mathrm{x}$ & $\mathrm{x}$ & $\mathrm{x}$ & $\mathrm{x}$ \\
\hline $\mathrm{UO}_{2}{ }^{36}$ & cF12 & $\mathrm{Fm} \overline{3} \mathrm{~m}(225)$ & $\begin{array}{l}\mathrm{a}=\mathrm{b}=\mathrm{c}=0.547[\mathrm{~nm}] \\
\alpha=\beta=\gamma=90^{\circ}\end{array}$ & $\mathrm{x}$ & $\mathrm{x}$ & $\mathrm{x}$ & $\mathrm{x}$ \\
\hline $\mathrm{Zr}_{2} \mathrm{Te}^{26}$ & oP36 & Pnma (62) & $\begin{array}{l}\mathrm{a}=1.995, \mathrm{~b}=0.382 \\
\mathrm{c}=1.065[\mathrm{~nm}] \\
\alpha=\beta=\gamma=90^{\circ}\end{array}$ & $\mathrm{x}$ & $\mathrm{x}$ & & \\
\hline $\mathrm{Zr}_{3} \mathrm{Te}^{37}$ & $\mathrm{tI} 32$ & $\mathrm{I} \overline{4}(82)$ & $\begin{array}{l}\mathrm{a}=\mathrm{b}=1.134, \mathrm{c}=0.563 \\
{[\mathrm{~nm}]} \\
\alpha=\beta=\gamma=90^{\circ}\end{array}$ & & & & $\mathrm{x}$ \\
\hline $\mathrm{NdTe}^{38}$ & cF8 & $\operatorname{Fm} \overline{3} \mathrm{~m}(225)$ & $\begin{array}{l}\mathrm{a}=\mathrm{b}=\mathrm{c}=0.627[\mathrm{~nm}] \\
\alpha=\beta=\gamma=90^{\circ}\end{array}$ & & & $\mathrm{x}$ & $\mathrm{x}$ \\
\hline $\mathrm{Nd}_{2} \mathrm{O}_{3}{ }^{39}$ & cI80 & Ia $\overline{3}(206)$ & $\begin{array}{l}\mathrm{a}=\mathrm{b}=\mathrm{c}=1.110[\mathrm{~nm}] \\
\alpha=\beta=\gamma=90^{\circ}\end{array}$ & & & $\mathrm{x}$ & $\mathrm{x}$ \\
\hline $\mathrm{Au}^{40}$ & cF4 & $\operatorname{Fm} \overline{3} \mathrm{~m}(225)$ & $\begin{array}{l}\mathrm{a}=\mathrm{b}=\mathrm{c}=0.408[\mathrm{~nm}] \\
\alpha=\beta=\gamma=90^{\circ}\end{array}$ & & & $\mathrm{x}$ & $\mathrm{x}$ \\
\hline
\end{tabular}

Table 3. Crystallographic information for all phases indexed through XRD analysis. ${ }^{a}$ Denotes the alloy in which the particular phase was detected through XRD analysis.

alloy also consist of $\mathrm{Te}$ and $\mathrm{Nd}$, and $\mathrm{Zr}$, respectively. However, the round black clustered precipitates are found to be primarily $\mathrm{Zr}$ with several containing Te. Furthermore, there does not appear to be precipitates that contain only Nd.

EDS point analysis conducted on various precipitates in each alloy is tabulated in Table 4 based on locations indicated in Fig. 4(a,b). The elemental composition of the grey-contrast precipitates, depicted by points 3-6, 10 and 11, indicates that they are likely the NdTe compounds. Analysis of the smaller grey-contrast precipitates in the $4 \mathrm{Te}-4 \mathrm{Nd}$ alloy (depicted by points $12-14$ ) indicates that they are more Te-rich than the NdTe (1:1) compound 

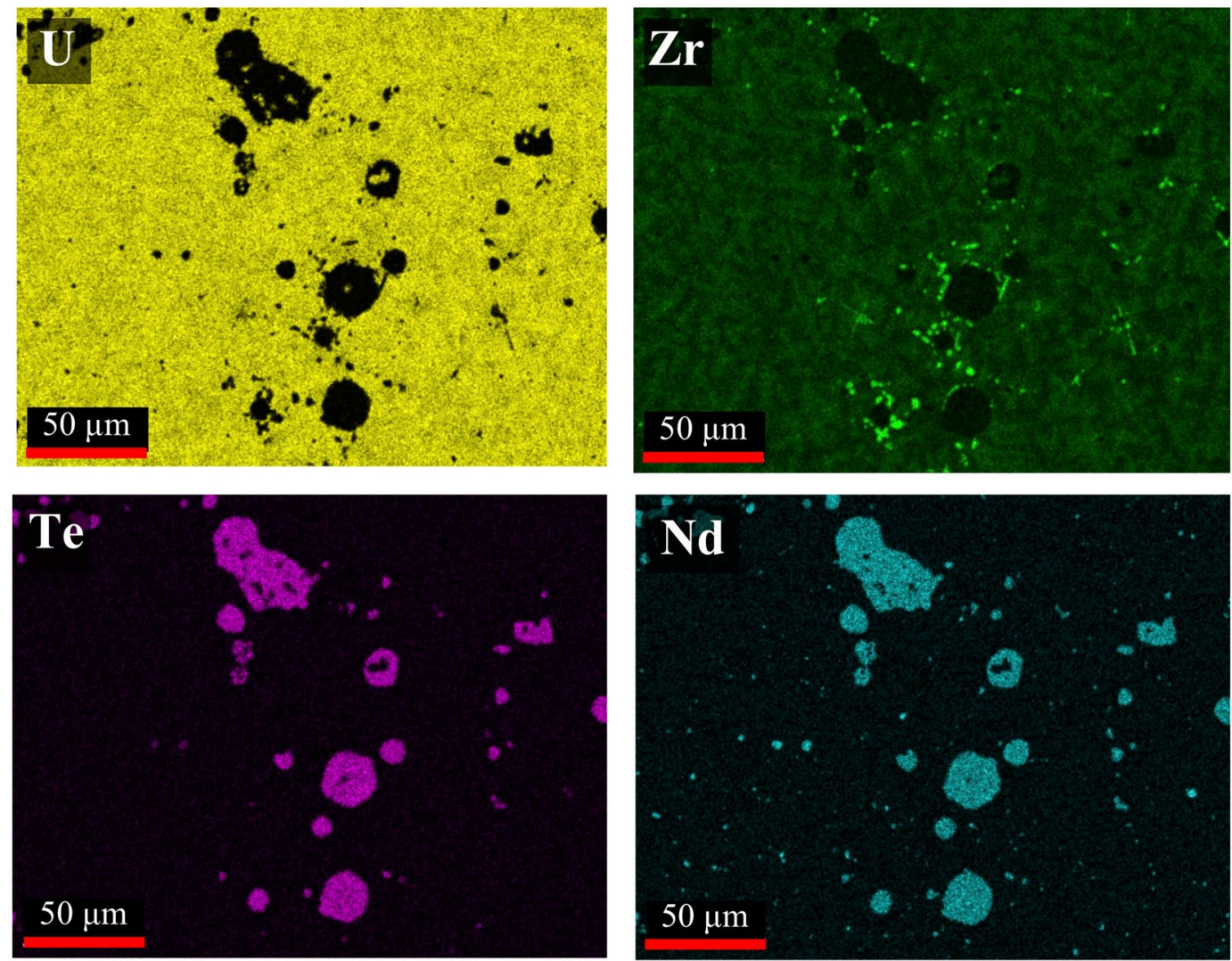

Figure 5. Elemental EDS maps of the 2Te-2Nd alloy. Analysis location aligns with the area imaged in Fig. 4(a).

but also contain appreciable amounts of $\mathrm{U}$ (20 at.\%, 12 at.\%, and 14 at.\%). Given the small size of the precipitates, some of the $\mathrm{U}$ detected could be from the alloy matrix due to the interaction volume of the electron beam. These Te-rich Nd-Te phases could either have uranium dissolved within or be the formation of a ternary U-Te-Nd phase. To resolve the exact nature of the precipitate, higher resolution characterization via transmission electron microscopy (TEM) was carried out on similar precipitates from the $4 \mathrm{Te}-4 \mathrm{Nd}$ alloy, which is discussed in detail below. Analysis of the very small (approximately 1-2 $\mu \mathrm{m}$ ) grey-contrast precipitates (point 9 ) in the $2 \mathrm{Te}-2 \mathrm{Nd}$ alloy were found to primarily consist of $\mathrm{Nd}$. The presence of pure $\mathrm{Nd}$ inclusions indicates the $\mathrm{Nd}$ concentration is in excess to that of Te within the alloy. This is further confirmed because no $\mathrm{Zr}$-Te containing compound phases were observed in the alloy and therefore all the Te available bound with the Nd.

The small, dendritic black precipitates observed in both alloys are found to consist of high concentrations of $\mathrm{Zr}$ (points 7, 8, 15, and 16 in Fig. 4). Such Zr-rich phases were not expected within the alloy. However, Janney and $\mathrm{O}^{\prime} H a l l e r a n^{27}$ observed similar Zr-rich phases in an as-cast structure of U-Zr with actinide and lanthanide additions. They found that the Zr-rich precipitates tend to form near lanthanide-containing precipitates, similar to what was observed here. They also suggested that such Zr-rich precipitates might get stabilized during casting and subsequent cooling due to trace impurities of $\mathrm{C}, \mathrm{N}$ and $\mathrm{O}$.

Evaluation of the larger round black precipitates (approximately 4-5 $\mu \mathrm{m}$ ) within the clusters (points 17 and 18 in Fig. 4b) in the 4Te-4Nd alloy indicates that they may be $\mathrm{Zr}_{3}$ Te compound; a more $\mathrm{Zr}$-rich compound than the $\mathrm{Zr}_{2}$ Te phases previously observed in the U-Zr-Te alloys. It should also be noted that points 17 and 18 indicate a higher $\mathrm{Zr}$ concentration than what would be expected in the $\mathrm{Zr}_{3} \mathrm{Te}$ compound. Given the size of the $\mathrm{Zr}-\mathrm{Te}$ precipitates and the fact that they are clustered within a $\mathrm{Zr}$-rich region of the $\mathrm{U}-\mathrm{Zr}$ matrix, the higher $\mathrm{Zr}$ content and presence of $U$ are most likely due to the beam interactions with the surrounding matrix. Because of the small size (submicron) of the clustered black precipitates, their accurate elemental composition could not be reliably assessed via SEM equipment used in this study.

To positively identify the phases of the smaller precipitates previously observed in the $4 \mathrm{Te}-4 \mathrm{Nd}$ alloy, TEM analysis was performed. The TEM specimen, shown in Fig. 7(a), was made using a focused ion-beam (FIB) lift-off technique targeting a similar precipitate to that observed between points 12 and 14 in Fig. 4(b). The fabricated TEM specimen included a Zr-Te precipitate similar to that at point 16. High-angle annular dark field (HAADF) images and selected area electron diffraction (SAED) patterns of the precipitates are presented in Fig. 7. SAED patterns were collected using multiple zone-axes of a single grain within the phase of interest. A SAED pattern from each analysis area is shown in Fig. $7(\mathrm{e}-\mathrm{g})$. The location of the grains used to generate SAED patterns are denoted by circles in the HAADF images of Fig. 7(b-d). EDS analysis was also performed on the TEM specimen to determine the elemental concentrations of the various precipitates. The analysis areas are denoted in the HAADF images of Fig. 7(b-d); the results are listed in Table 5. 

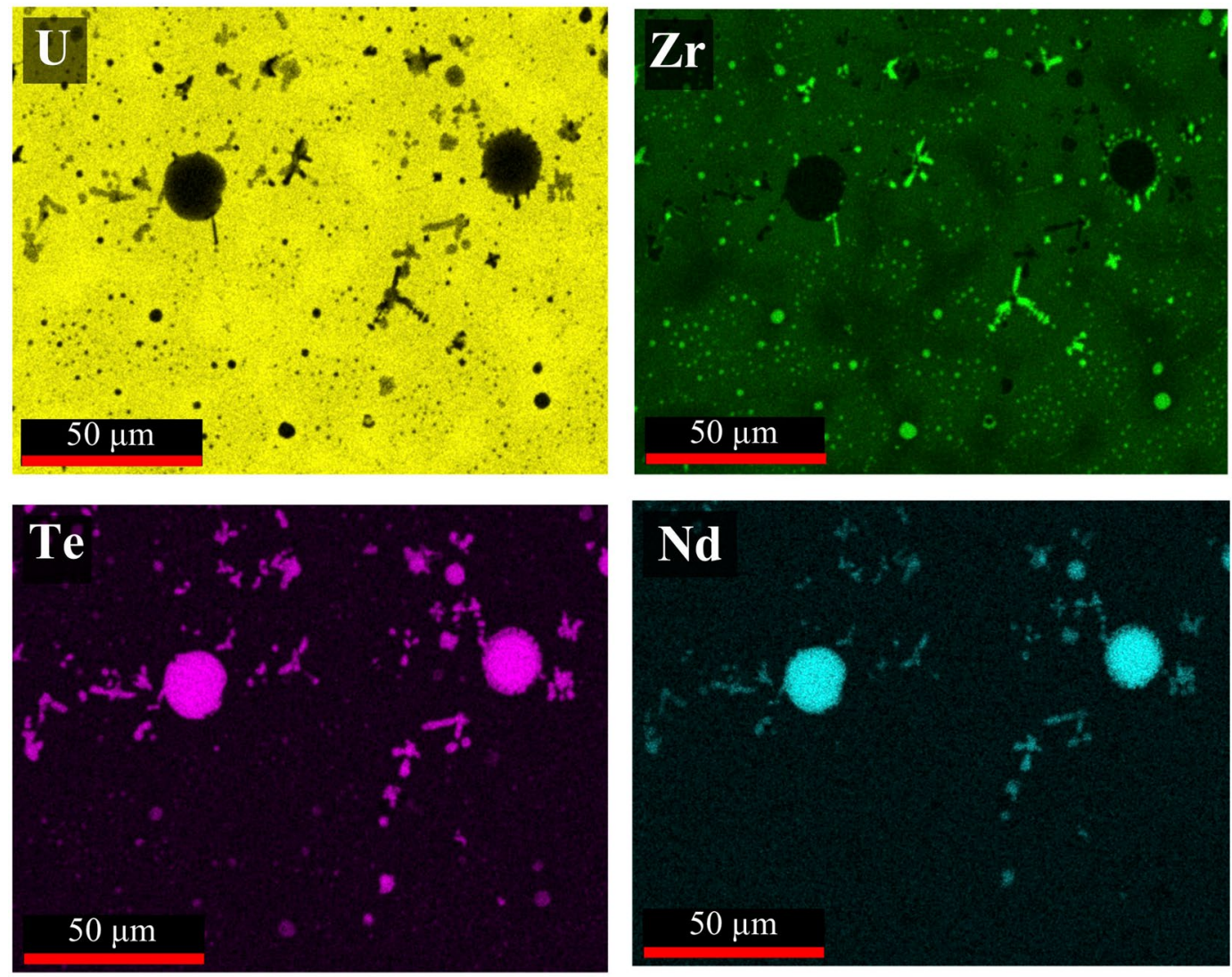

Figure 6. Elemental EDS X-ray maps of the $4 \mathrm{Te}-4 \mathrm{Nd}$ alloy. Analysis location aligns with the area imaged in Fig. 4(b).

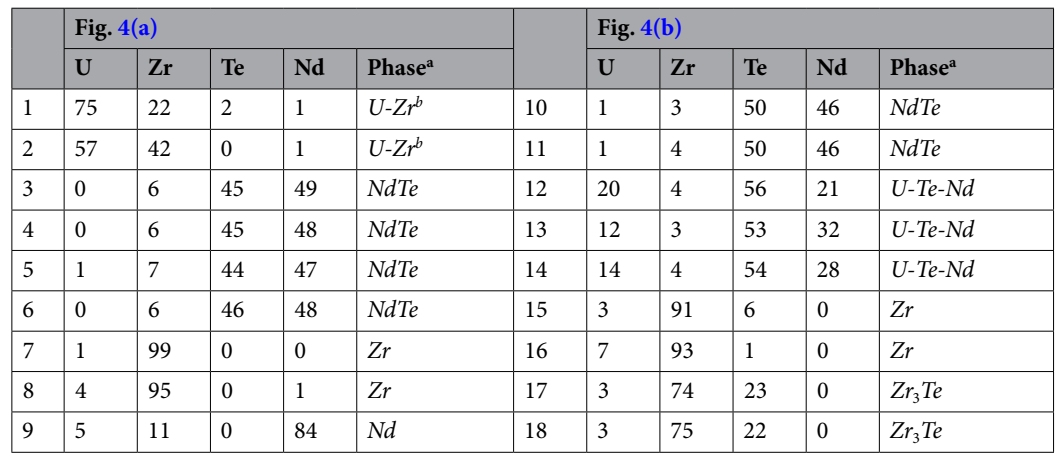

Table 4. SEM EDS elemental data results of analysis points depicted in Fig. 4(a,b) (in at.\%). ${ }^{\text {a }}$ Suggested phase based on EDS analysis. ${ }^{b}$ Matrix phase of the as-cast U-Zr alloy.

The HAADF micrographs shown in Fig. 7(b-d) exhibit different types of precipitates. Elemental analysis of the lighter grey-contrast phases, depicted by points 1,6 and 7, indicates that they are the combination of $\mathrm{Nd}, \mathrm{Te}$ and U; similar to points 12-14 in Table 4. SAED patterns, obtained from locations $A$ and $B$ in Fig. 7(b,c) respectively, are both found to index with the NdTe and UTe compounds, both of which are cubic and have similar crystallographic characteristics (Table 6). The formation of UTe precipitates within an alloy containing both Zr and $\mathrm{Nd}$ is not likely based on the thermodynamic characteristics of $\mathrm{U}-\mathrm{Te}, \mathrm{Zr}$-Te and $\mathrm{Nd}-\mathrm{Te}$; as discussed further in the computational section later. Other potential binary compounds were considered $-\mathrm{Nd}_{2} \mathrm{Te}_{3}, \mathrm{NdTe}_{2}, \mathrm{Nd}_{2} \mathrm{Te}_{5}$, and $\mathrm{NdTe}_{3}$ - albeit none were found to match with the SAED patterns of a given grain. The few U-Nd-Te ternary compounds noted in literature were considered - $\mathrm{UTe}_{4} \mathrm{Nd}_{2}, \mathrm{UTe}_{5} \mathrm{Nd}_{2}$, and $\mathrm{UTe}_{6} \mathrm{Nd}-$ but none could be indexed with the SAED patterns. The existence of stable U-Te-Nd compounds indicates that the formation of such a ternary phase is possible. It is worth noting that the $\mathrm{U}-\mathrm{Te}-\mathrm{Nd}$ phases documented in literature are Te-rich, which is a similar scenario to those precipitates analyzed in Fig. 7(b,c). Hence, due to the lack of a U-Te-Nd ternary phase diagram, the possibility that $\mathrm{U}-\mathrm{Te}-\mathrm{Nd}$ precipitates analyzed in this study being an undocumented ternary phase cannot be ruled out. 

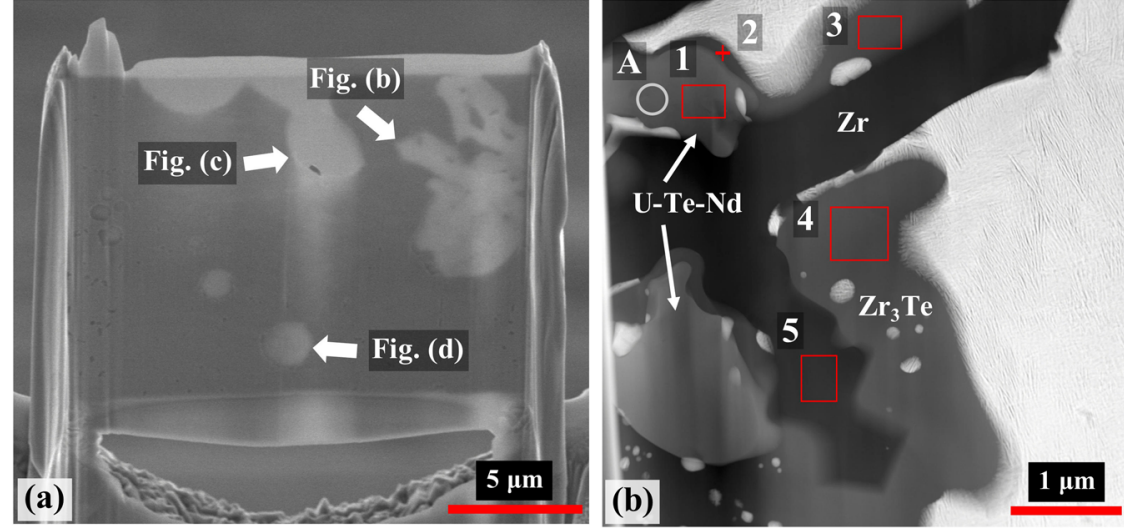

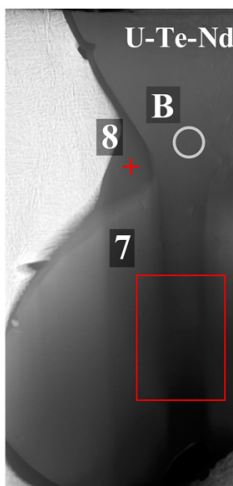

(c)
6

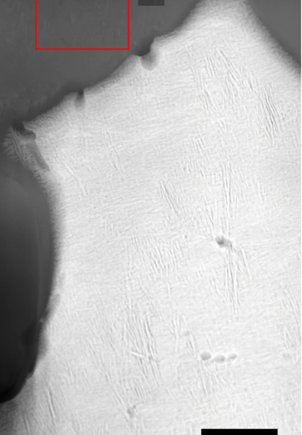

$1 \mu \mathrm{m}$

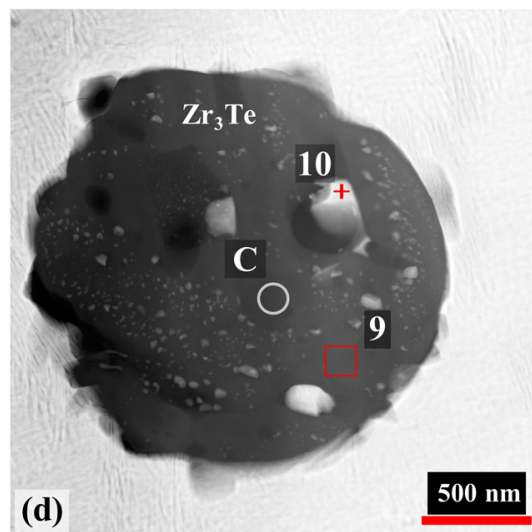

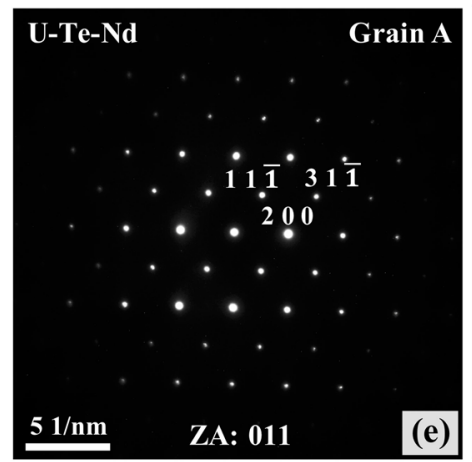
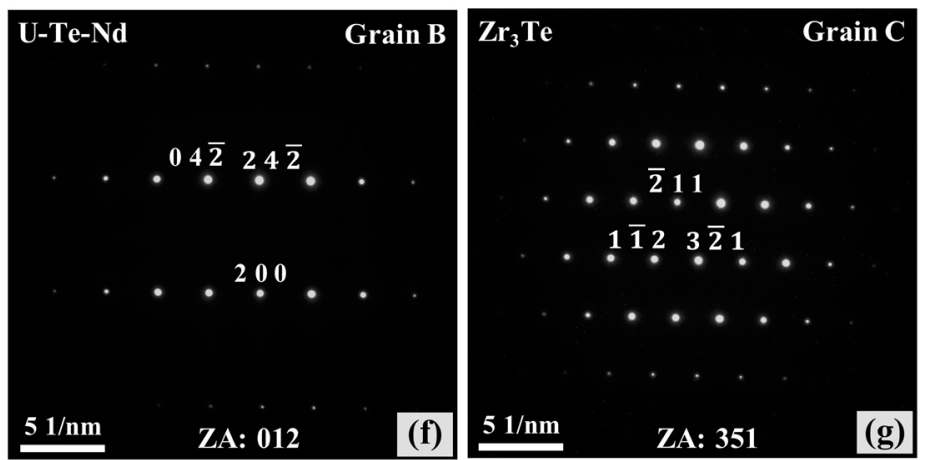

Figure 7. TEM analysis results of precipitates in the 4Te-4Nd alloy. (a) SEM image of the TEM lamella, and HAADF micrographs of (b) U-Te-Nd, Zr-Te, and Zr precipitates; (c) U-Te-Nd precipitate; and (d) Zr-Te precipitate. Single zone-axis SAED patterns from (e) grain $A$ along the [011] zone axis, (f) grain $B$ along the [012] zone axis, and (g) grain $C$ along the [351] zone axis.

\begin{tabular}{|c|c|c|c|c|c|c|c|c|c|c|c|}
\hline & \multicolumn{5}{|c|}{ Fig. 7(b) } & & \multicolumn{5}{|c|}{ Fig. 7(c,d) } \\
\hline & $\mathbf{U}$ & $\mathbf{Z r}$ & $\mathrm{Te}$ & Nd & Phase $^{\mathrm{a}}$ & & $\mathbf{U}$ & $\mathrm{Zr}$ & $\mathrm{Te}$ & Nd & Phase $^{a}$ \\
\hline 1 & 42.1 & 2.3 & 42.8 & 12.9 & U-Te-Nd & 6 & 38.1 & 0.9 & 39.6 & 21.3 & $U-T e-N d$ \\
\hline 2 & 7.1 & 78.5 & 14.4 & 0 & $\mathrm{Zr}_{3} \mathrm{Te}$ & 7 & 40.7 & 0 & 44 & 15.3 & U-Te-Nd \\
\hline 3 & 3.4 & 77.6 & 18.8 & 0.2 & $\mathrm{Zr}_{3} \mathrm{Te}$ & 8 & 1.7 & 75.4 & 21.5 & 1.5 & $\mathrm{Zr}_{3} \mathrm{Te}$ \\
\hline 4 & 4.0 & 76.5 & 19.4 & 0.1 & $\mathrm{Zr}_{3} \mathrm{Te}$ & 9 & 3.0 & 76.5 & 19.2 & 1.4 & $\mathrm{Zr}_{3} \mathrm{Te}$ \\
\hline 5 & 0.3 & 99.6 & 0.1 & 0 & $Z r$ & 10 & 83.2 & 16.3 & 0.3 & 0.2 & $U-Z r^{b}$ \\
\hline
\end{tabular}

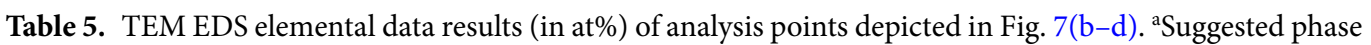
based on EDS analysis. ${ }^{b}$ Matrix phase of the as-cast U-Zr alloy.

A medium grey-contrast phase is also found to be present in the HAADF images of Fig. 7. This phase is observed to occupy a large portion of the precipitate phases formed in Fig. 7(b), in addition to forming as a layer surrounding the U-Te-Nd containing precipitates (Fig. $7(\mathrm{~b}, \mathrm{c})$ ). It also appears to be the primary phase present in 


\begin{tabular}{|l|l|l|l|}
\hline Compound & Pearson Symbol & Space Group & Cell Parameters \\
\hline $\mathrm{NdTe}^{41}$ & $\mathrm{cF} 8$ & $\mathrm{Fm} \overline{3} \mathrm{~m}(225)$ & $\begin{array}{l}\mathrm{a}=b=c=0.627[\mathrm{~nm}] \\
\alpha=\beta=\gamma=90^{\circ}\end{array}$ \\
\hline $\mathrm{UTe}^{42}$ & $\mathrm{cF} 8$ & $\mathrm{Fm} \overline{3} \mathrm{~m}(225)$ & $\begin{array}{l}a=b=c=0.615[\mathrm{~nm}] \\
\alpha=\beta=\gamma=90^{\circ}\end{array}$ \\
\hline $\mathrm{Zr}_{3} \mathrm{Te}^{43}$ & $\mathrm{t} 132$ & $\mathrm{I} \overline{4}(82)$ & $\begin{array}{l}a=b=1.134, c=0.563 \\
{[\mathrm{~nm}]} \\
\alpha=\beta=\gamma=90^{\circ}\end{array}$ \\
\hline
\end{tabular}

Table 6. Crystallographic details from determined phases from SAED patterns presented in Fig. 7(e-g).
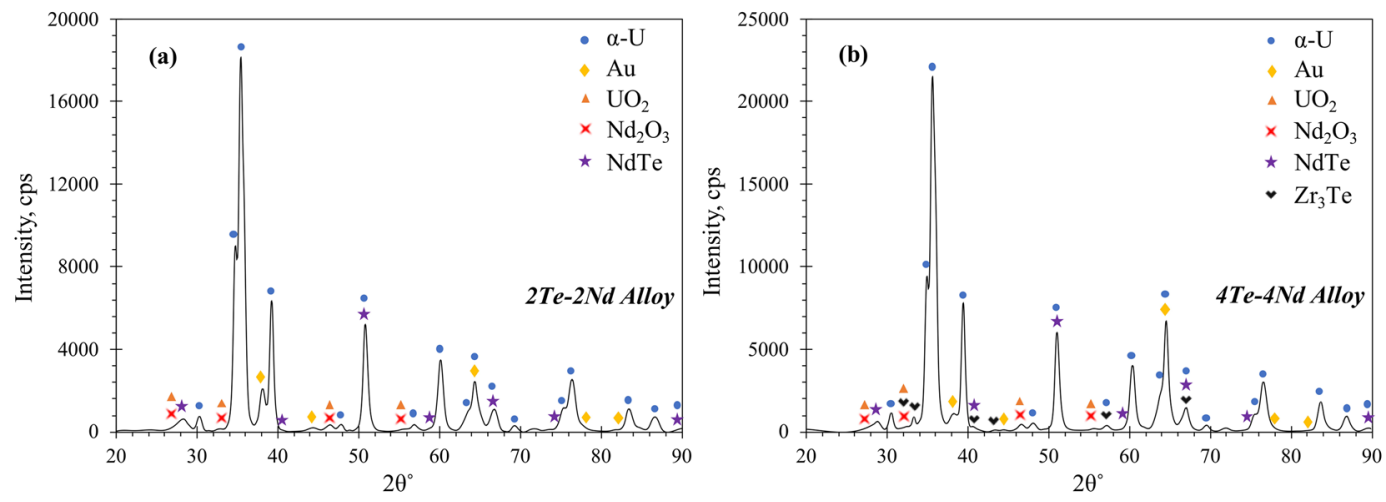

Figure 8. XRD patterns of (a) the $2 \mathrm{Te}-2 \mathrm{Nd}$ alloy and (b) the $4 \mathrm{Te}-4 \mathrm{Nd}$ alloy.

the globular precipitate of Fig. 7(d). Analysis of this phase (points 2-4, 8 and 9) indicates that it is a $\mathrm{Zr}$-Te containing phase and based on the atomic ratio of the various points it appears to be the $\mathrm{Zr}_{3} \mathrm{Te}_{\mathrm{c}}$ compound. Diffraction analysis performed on location $C$ (Fig. 7(d)) confirms this phase to be $\mathrm{Zr}_{3} \mathrm{Te}$. $\mathrm{The}_{\mathrm{Zr}} \mathrm{Te}$ precipitates are observed to contain small white inclusions of varying sizes. EDS analysis of these inclusions observed in both Fig. 7(b,d), point 10 , indicates these inclusions are in fact $\mathrm{U}-\mathrm{Zr}$ precipitates matching that of the U-Zr matrix. Higher magnification of the $\mathrm{Zr}_{3}$ Te precipitates showed a fine dispersion of such inclusions measuring $10-50 \mathrm{~nm}$ in width. The presence of such inclusions would explain why the precipitates appear to be more $\mathrm{Zr}$-rich than the $\mathrm{Zr}_{3} \mathrm{Te}$ compound as well as explain the presence of $U$ contained within the $\mathrm{Zr}_{3} \mathrm{Te}$ precipitates. The middle of the precipitate in Fig. 7(b) contains a dark phase and as indicated by point 5, is found to be a $\mathrm{Zr}$-rich inclusion, similar to those previously observed through SEM analysis (points 7, 8, 15, and 16 in Table 4).

Focused XRD analysis was also performed on the $2 \mathrm{Te}-2 \mathrm{Nd}$ and $4 \mathrm{Te}-4 \mathrm{Nd}$ alloys, the plots of which are presented in Fig. 8(a,b), respectively. The corresponding crystallographic information of the indexed phases are listed in Table 3. The diffraction patterns for both alloys indicate that each is comprised primarily of the $\alpha-U$ phase. Both alloys also exhibit peaks for the sputtered coating of $\mathrm{Au}$, which was not removed prior to XRD analysis. Both diffraction plots confirm the presence of the NdTe compound, albeit with limited peak intensities. However, such limited intensities would be expected given the compound is only present in the alloy as dispersed precipitates, which were observed to be no larger than $25 \mu \mathrm{m}$. As with SAED, no U-Te-Nd ternary phase could be indexed in the XRD patterns. The $\mathrm{Zr}_{3} \mathrm{Te}$ phase is indexed in the XRD pattern of the $4 \mathrm{Te}-4 \mathrm{Nd}$ alloy, further confirming its presence in the alloy. Traces of both $\mathrm{UO}_{2}$ and $\mathrm{Nd}_{2} \mathrm{O}_{3}$ were found in both diffraction patterns, and the formation of $\mathrm{UO}_{2}$ is, again, likely the result of surface oxidation. The formation of $\mathrm{Nd}_{2} \mathrm{O}_{3}$ can likely be attributed to the combination of surface oxidation and trace amounts of residual oxidation on the $\mathrm{Nd}$ feedstock materials that got mixed into the alloy.

In the $2 \mathrm{Te}-2 \mathrm{Nd}$ alloy, all the precipitate phases observed were of NdTe type. This points toward the fact that during the final casting step, when $\mathrm{Nd}$ was added to the $\mathrm{U}-\mathrm{Zr}$-Te alloy, the existing $\mathrm{Zr}_{2} \mathrm{Te}$ precipitates decomposed, releasing Te to form new precipitates with $\mathrm{Nd}$. The formation of the $\mathrm{NdTe}$ compound is favorable, and according to the $\mathrm{Nd}$-Te binary phase diagram it exhibits high temperature stability $\left(T_{\text {melt }}=2025^{\circ} \mathrm{C}^{28}\right)$, which can aid in mitigating availability of Nd to participate in processes leading to FCCI. Characterization of the $4 \mathrm{Te}-4 \mathrm{Nd}$ alloy revealed the formation of several compounds - NdTe and $\mathrm{Zr}_{3} \mathrm{Te}$ as well as a possible U-Te-Nd ternary phase. However, it is important to note that no free $\mathrm{Nd}$ was observed in the alloy. This indicates that all available Nd was bound with Te. Therefore, the formation of other Te-based compounds, $\mathrm{Zr}$-Te and U-Te-Nd, would indicate the alloy was Te-rich at this particular analysis plane and the 1:1 additive - lanthanide ratio was not maintained. It is worth recalling that the initial alloys were cast slightly additive-rich and thus the formation of other Te-based compounds beyond $\mathrm{Nd}$-Te could be an indication that less Te may have been lost during casting than what was initially assumed. Regardless, the presence of $\mathrm{Nd}$-Te precipitates demonstrates their propensity to form preferably over Zr-Te compounds. 


\begin{tabular}{|l|l|}
\hline Composition & Enthalpy of mixing \\
\hline $\mathrm{U}-\mathrm{Te}$ & $0.16 \mathrm{eV}$ \\
\hline $\mathrm{U}-\mathrm{Zr}-\mathrm{Te}$ & $-0.28 \mathrm{eV}$ \\
\hline $\mathrm{U}-\mathrm{Zr}-\mathrm{Nd}$ & $2.54 \mathrm{eV}$ \\
\hline $\mathrm{U}-\mathrm{Nd}-\mathrm{Te}$ & $-3.23 \mathrm{eV}$ \\
\hline $\mathrm{U}-\mathrm{Zr}-\mathrm{Nd}-\mathrm{Te}$ & $-1.48 \mathrm{eV}$ \\
\hline
\end{tabular}

Table 7. Enthalpy of mixing values (as predicted by DFT) for different elements in various systems. A negative enthalpy indicates ease of formation of the stable compound.

(a)
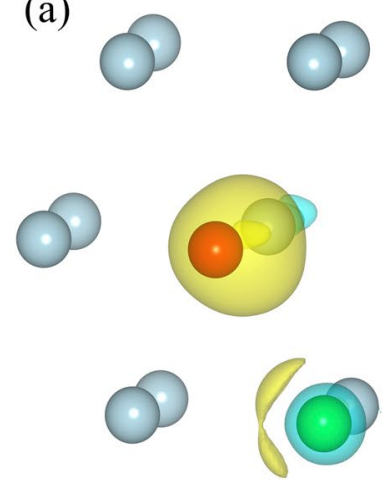

(b)
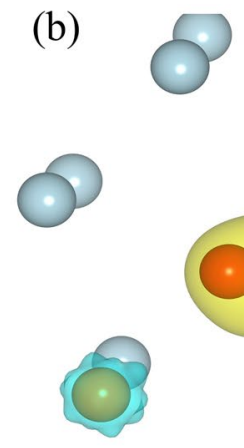

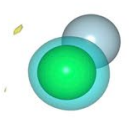

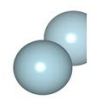
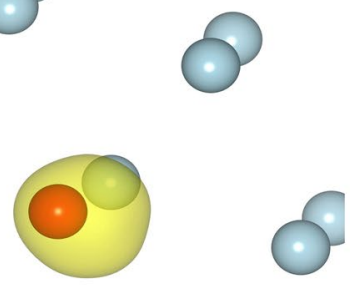

Figure 9. The charge density difference (CDD) between (a) U-Zr-Te and U and (b) U-Nd-Zr-Te and U systems; the yellow isosurface represents excess charge, and the blue isosurface represents a charge deficit or the negative value of charge density. Note that the figures were created by VESTA 3.0 software, https://onlinelibrary.wiley. com/iucr/doi/10.1107/S0021889811038970.

Computational prediction of phases. Formation of different compounds observed experimentally as well as the mutual interactions between $\mathrm{Te}, \mathrm{Nd}$ and $\mathrm{Zr}$ can be understood from first principles calculations based on density functional theory (DFT) ${ }^{16}$. DFT calculated enthalpy of mixing (Table 7) for different elements was used as a guidance to predict preferred compound formation tendencies. For each composition in Table 7 the element at the end is the one for which enthalpy of mixing was calculated within a matrix containing all the previous element(s). The enthalpy of mixing of Te inside the $\alpha-U$ matrix is slightly positive, i.e., $0.16 \mathrm{eV}$, whereas that of Te in the U-Zr system is negative, $-0.28 \mathrm{eV}$. This indicates that Te will bind with the Zr within the U-matrix. Indeed, formation of the $\mathrm{Zr}_{2}$ Te phase was observed in the U-Zr-Te alloys, as shown in Fig. 1. Further, the enthalpy of mixing of $\mathrm{Nd}$ inside the $\mathrm{U}-\mathrm{Zr}$ matrix is $2.54 \mathrm{eV}$. This positive enthalpy of mixing indicates a phase-separating tendency of $\mathrm{Nd}$ in the $\mathrm{U}-\mathrm{Zr}$ matrix and thus it is understandable why no $\mathrm{Nd}$ containing compound was observed within the U-Zr system. On the other hand, the enthalpy of mixing for Te in the U-Zr-Nd system is $-1.48 \mathrm{eV}$ and that in $\mathrm{U}-\mathrm{Nd}$ is $-3.23 \mathrm{eV}$, suggesting a strong compound forming tendency of Te with $\mathrm{Nd}$ regardless of presence or absence of $\mathrm{Zr}$ within the U-matrix. With the enthalpy of mixing of Te being more negative in both U-Zr-Nd $(-1.48 \mathrm{eV})$ and $\mathrm{U}-\mathrm{Nd}(-3.23 \mathrm{eV})$ compared to the enthalpy of mixing of $\mathrm{Te}$ in $\mathrm{U}-\mathrm{Zr}(-0.28 \mathrm{eV})$, the interactions between $\mathrm{Nd}$ and $\mathrm{Te}$ are expected to be stronger than the interactions between $\mathrm{Zr}$ and Te. Thus, it can be concluded that the phase stability in the ternary and in quaternary U-Zr-Nd-Te system can be inferred based on binary interactions between the elements involved (e.g.: Zr-Te interactions vs. Nd-Te interactions).

Furthermore, to understand the interactions between the elements the charge density differences (CDD) have been calculated, as depicted in Fig. 9. The CDD is calculated by taking the difference in the calculated charge densities between final configurations with multiple elements and a pristine $U$-matrix at each atomic position. From Fig. 9(a), the charge transfer (indicated by a yellow isosurface) observed from $\mathrm{Zr}$ to Te indicates a potential electronic interaction between the elements. Such electronic interaction is one of the reasons for the negative enthalpy of mixing that was calculated for Te in the $\mathrm{U}-\mathrm{Zr}$ matrix. Also, when there is $\mathrm{Nd}$ and $\mathrm{Te}$ in the system together with $\mathrm{Zr}$, as shown in Fig. 9(b), the charge is noted to transfer from both $\mathrm{Nd}$ and $\mathrm{Zr}$ towards Te. The excess charge on $\mathrm{Te}$ (yellow isosurface) and the charge deficient region on both $\mathrm{Nd}$ and $\mathrm{Zr}$ (blue isosurface) indicate the attractive interaction of Te with $\mathrm{Zr}$ and $\mathrm{Nd}$, which may lead to the formation of a stable compound. A similar interaction was observed between $\mathrm{Nd}$ and $\mathrm{Te}$ in the system when $\mathrm{Zr}$ was absent in the $\mathrm{U}$-matrix ${ }^{16}$.

To gain a detailed understanding of the interactions between $\mathrm{Nd}, \mathrm{Te}$, and $\mathrm{Zr}$, the partial density of states (DOS) have been plotted for Te and Nd in U-Zr-Te-Nd and U-Te-Nd systems, as shown in Fig. 10(a,b), respectively. The occupied $4 f$ states of Nd lies below the Fermi level and is localized between -5 to $-4 \mathrm{eV}$, while the unoccupied $4 f$ states are above the Fermi level. Furthermore, Fig. 10 shows that localized Nd $4 f$ orbitals (solid magenta lines) located between -5 to $-4 \mathrm{eV}$ interact with Te (solid green lines) via valence electrons (orbital hybridization), namely, $p$ electrons of Te (indicated by the shaded region). The overlapping of the valence orbitals of the additive Te with the $\mathrm{Nd} f$ orbitals, as shown in Fig. 10(b), was also found to be the key indication for other additives such as Se and As, 

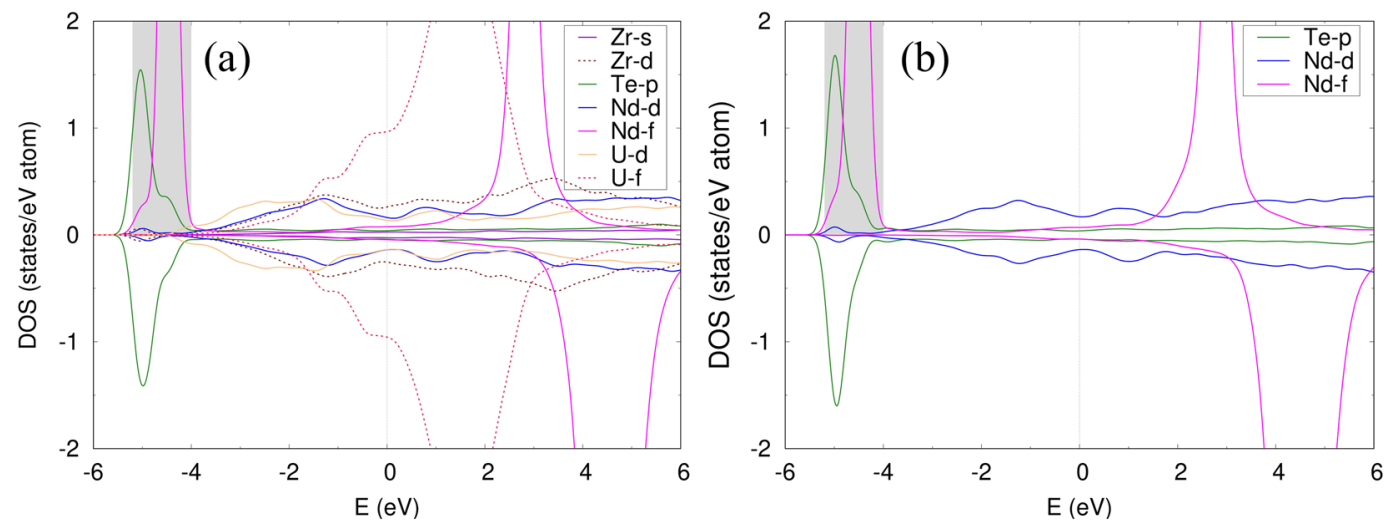

Figure 10. Orbital resolved DOS for (a) U-Zr-Te-Nd and (b) U-Te-Nd. The vertical dashed lines represent the Fermi level, the energy states up to which states are occupied. The states in the negative and positive vertical axis represent down and up spin components, respectively. U-DOS remain more or less similar in all systems.

which were shown to be effective in binding with $\mathrm{Nd}$ inside the $\mathrm{U}$-matrix ${ }^{16}$. Hence, from the comparison of both the enthalpy of mixing for Te in U-Zr-Nd and U-Nd matrices as well as the density of states shown in Fig. 10(a,b), it can argued that $\mathrm{Te}$ is an effective candidate additive to bind with $\mathrm{Nd}$ inside the fuel matrix (U-Zr system).

Results from DFT calculations support the observations made in the characterization of the alloys of interest. The calculations show that the $\mathrm{Zr}$-Te interaction is favorable within the U-Zr-Te alloys. On the other hand, the $\mathrm{Nd}-\mathrm{Te}$ interactions appear to be even more favorable than $\mathrm{Zr}-\mathrm{Te}$, and thus as the fission product $\mathrm{Nd}$ forms within the $\mathrm{U}-\mathrm{Zr}$-Te alloys, Te is expected to bind with $\mathrm{Nd}$ instead of binding with $\mathrm{Zr}$.

\section{Conclusions}

To summarize, both experimental and DFT calculations confirm that binary interactions of Te with both Zr and $\mathrm{Nd}$ dominates the phase formations within the multi-component $\mathrm{U}-\mathrm{Zr}$-Te and U-Zr-Te-Nd alloys. In the ternary $\mathrm{U}-\mathrm{Zr}$-Te alloys, the binary interaction between $\mathrm{Te}$ and $\mathrm{Zr}$ was observed to be dominant through the formation of $\mathrm{Zr}_{2}$ Te precipitates. In the quaternary $\mathrm{U}-\mathrm{Zr}$-Te-Nd alloys the binary interactions of Te with $\mathrm{Nd}$ and $\mathrm{Zr}$ were both observed through the formation of $\mathrm{NdTe}$ and $\mathrm{Zr}_{3} \mathrm{Te}$ compounds, where the latter phase likely formed due to a Te concentration that exceeded the available Nd. Further, it was concluded that ternary interactions could be plausible through the formation of an unconfirmed U-Te-Nd compound.

It is apparent that $\mathrm{Te}$ can be an effective additive to bind with $\mathrm{Nd}$ within the $\mathrm{U}-\mathrm{Zr}$ matrix. Furthermore, the formation of stable, high-melting point, $\mathrm{Nd}-\mathrm{Te}$ compounds has the potential to stabilize the lanthanide within the fuel, and thus counteract its participation in the FCCI phenomenon. However, further work is necessary to evaluate the stability of the $\mathrm{Nd}$-Te interactions in the non-equilibrium state experienced within an irradiation environment. Additionally, the FCCI phenomenon is driven by diffusion-based mechanisms and therefore further studies on the diffusion interactions of U-Zr-Te-Nd alloys with potential claddings alloys, such as HT-9, are being conducted to further examine the effectiveness of Te as a fuel additive to mitigate FCCI.

Methodology. Experimental methods. Raw materials, such as zirconium, tellurium and neodymium, were acquired from Alfa Aesar company. Neodymium was received as a rod packaged in mylar under argon. Uranium, depleted in the ${ }^{235} \mathrm{U}$ isotope to $0.22 \%$, was initially cleaned by submersion in nitric acid, followed by a water wash and a subsequent ethanol wash.

Alloys were cast using an arc-melter, with high purity argon as a cover gas, contained within an argon glovebox. To achieve a homogeneous alloy, the button was melted and flipped three times after each element addition. The $\mathrm{U}-10 \mathrm{Zr}$-Te alloys were cast using a two-step process, whereas the U-10Zr-Te-Nd alloys were cast using a three-step process. Initially, the uranium and zirconium were added to create a pre-alloy of U-10Zr (wt\%). For all four alloys tellurium was added to the $\mathrm{U}-10 \mathrm{Zr}$ buttons in the second step at the appropriate concentration; the button was only flipped and re-melted twice in this step to limit loss of the additive. For the U-10Zr-Te-Nd alloys, neodymium was added to the U-10Zr-Te buttons in the third step at the appropriate concentrations to generate the simulated fuel alloys of interest. The alloys were then drop-cast to form pins with a diameter of approximately $5 \mathrm{~mm}$.

A sample of each alloy pin was sectioned and mounted in a phenolic resin ring and epoxy for microstructural characterization. Samples were prepared by grinding using 320 grit SiC papers to achieve a uniform plane on the sample surface followed by sequential polishing steps with $9 \mu \mathrm{m}, 3 \mu \mathrm{m}$ and $1 \mu \mathrm{m}$ polycrystalline diamonds suspended in an ethylene glycol solution. Final polishing steps of the samples were performed within an argon glovebox to limit surface oxidation. The polished surfaces were then sputtered with a $9 \mathrm{~nm}$ layer of gold to control charging of the metallographic mount within scanning electron microscope.

Scanning electron microscopy (SEM) was performed using a JEOL JSM-6610LV operated at an accelerating voltage of $20 \mathrm{kV}$. Imaging of the sample was primarily conducted using the backscatter electron imaging mode (BSE) to provide better contrast of the different phase formations. Energy dispersive x-ray spectroscopy (EDS) was conducted on the SEM in secondary electron (SE) mode using an EDAX Apollo X silicon drift detector (SDD) and the EDAX TEAM v4.4 (2016) software. The amp time, which is the time interval that $\mathrm{X}$-ray energy absorption is processed at the 


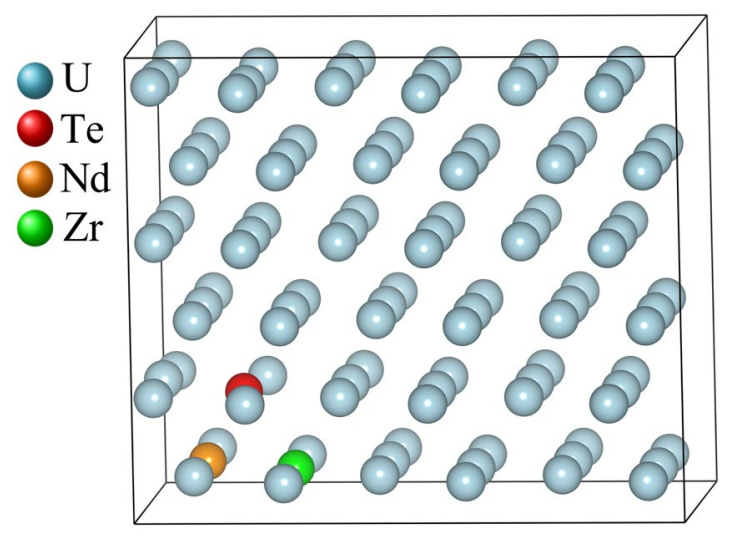

Figure 11. DFT optimized configuration of U-Zr-Te-Nd system. Note that the figure was created by VESTA 3.0 software, https://onlinelibrary.wiley.com/iucr/doi/10.1107/S0021889811038970.

detector, was adjusted for each analysis to generate a dead time of approximately $30 \%$. In conducting point analysis, elemental spectra were collected for 50 live seconds per analysis location. In generating elemental X-ray maps a dwell time of $200 \mu$ s was used. Elemental data from EDS was quantified based on the standardless ZAF method, which relies on the EDAX TEAM library of stored spectra of standards. Furthermore, it is largely understood that such quantification can have a statistical error of between 2-5\%. Transmission electron microscope (TEM) specimens were prepared on a FEI Quanta 3D FEG dual-beam microscope using a focused ion beam (FIB) lift-off technique. The TEM study was conducted using a Tecnai G2 F30 at an accelerating voltage of $300 \mathrm{kV}$. Both selected area electron diffraction (SAED) patterns and EDS data were collected using bright-field (BF) and high-angle annular dark field (HAADF) detectors. X-ray diffraction (XRD) was performed using a Rigaku SmartLab X-Ray Diffractometer paired with SmartLab Guidance software (v2.0.4.7). The diffractometer was operated at a set tube current of $44 \mathrm{~mA}$ using $\mathrm{Cu} \mathrm{K \alpha}$ radiation. Analysis was conducted with the optics set in the medium focus, parallel beam (PB) mode paired with a D/tex Ultra $2501 \mathrm{D}$ silicon strip detector. Focused XRD $\theta / 2 \theta$ scans were conducted at several locations on the sample surface using a $0.04^{\circ}$ step size and a scan speed of $2^{\circ} / \mathrm{min}$. Data was analyzed and indexed using Rigaku's PDXL 2 software (v2.3.1.0) utilizing the International Centre for Diffraction Data (ICDD) (PDF-2 Release 2016) database for XRD pattern indexing.

Computational methods. All calculations were performed using the density functional theory (DFT) as implemented in the Vienna Ab initio Simulation Package (VASP) ${ }^{29,30}$. Computational details including the choice of $U$ for GGA $+U$ can be found in the work of Khanal et al. ${ }^{16}$. The following procedure was adopted in adding elements within the supercell. First a $\mathrm{U}$ atom was substituted with atom A (either $\mathrm{Nd}, \mathrm{Zr}$ or Te atom) on a fully optimized $3 \times 3 \times 3$ supercell of $\alpha$-U, $\mathrm{Cmcm}$ (orthorhombic) structure ${ }^{31}$, followed by a re-optimization of the atomic coordinates. After obtaining a newly DFT-optimized atom substituted system, another U-atom at the first nearest neighbor position to atom $A$ was substituted with atom $B$, and the internal coordinates of the final structure at a fixed volume were optimized again. It is notable that for the quaternary U-Zr-Te-Nd system, several atomic configurations are possible among elements. For finding the most stable configuration of the U-Zr-Te- $\mathrm{Nd}$ system, sixteen different possible configurations were created by considering all nearest neighbor non-equivalent arrangements of the third element by fixing two elemental pairs at a time, i.e. $\mathrm{Nd}-\mathrm{Te}, \mathrm{Zr}-\mathrm{Te}$ or $\mathrm{Nd}-\mathrm{Zr}$. Atomic positions for each configuration were optimized, and the most stable, i.e. minimum energy, configuration among all potential sixteen configurations was chosen for further study. Figure 11 shows an optimized structure of $\mathrm{Nd}$ and Te substituted within the U-Zr matrix.

Equation (1) shows a typical equation used to calculate the enthalpy of mixing of an element B in an U-A matrix (Table 7) $)^{32,33}$ :

$$
\Delta E_{\text {mixing }}=E\left(\mathrm{U}_{n-2} \mathrm{AB}\right)+E(\mathrm{U})-E\left(\mathrm{U}_{n-1} \mathrm{~A}\right)-E(\mathrm{~B}),
$$

in which $E\left(\mathrm{U}_{n-2} \mathrm{AB}\right)$ is the total energy of $(n-2) \mathrm{U}$ atoms, one $\mathrm{A}$ and one $\mathrm{B}$ atom in a simulation cell of $n$ sites; $E\left(\mathrm{U}_{n-1} \mathrm{~A}\right)$ is the total energy of $(n-1) \mathrm{U}$ atoms and one A atom in a simulation cell of $n$ sites; and $E(\mathrm{~B})$ and $E(\mathrm{U})$ are the total energy per atom for $B$ and $U$, respectively. Here, negative enthalpy indicates ease of formation of the stable compounds whereas positive enthalpy represents less tendency for the formation of a stable compound. The concept of mixing enthalpy in the formation of intermetallic compounds has been previously used in studying the stability of high entropy alloys (HEA) ${ }^{34,35}$.

\section{Data availability}

Data generated and analyzed in the current study will be made available upon request to the corresponding author.

Received: 21 June 2019; Accepted: 4 October 2019;

Published online: 05 November 2019 


\section{References}

1. Crawford, D. C., Porter, D. L. \& Hayes, S. L. Fuels for sodium-cooled fast reactor: US perspective. J. Nucl. Mater. 371(1-3), 202-231, https://doi.org/10.1016/j.jnucmat.2007.05.010 (2007).

2. Ogata, T. Metal Fuel. Compr. Nucl. Mater. 3, 1-40, https://doi.org/10.1016/B978-0-08-056033-5.00049-5 (2012).

3. Carmack, W. J. et al. Metallic fuels for advanced reactors. J. Nucl. Mater. 392(2), 139-150, https://doi.org/10.1016/j. jnucmat.2009.03.007 (2009)

4. Keiser, D. D. Metal fuel-cladding interaction. Compr. Nucl. Mater. 3, 423-441, https://doi.org/10.1016/B978-0-08-056033-5.00067-7 (2012).

5. Arnold, C. W., Galloway, J. \& Unal, C. Towards understanding FCCI: modeling cerium solid transport in metal fuels. Trans. American Nucl. Society 112, 269-270 (June 2015).

6. Mariani, R. D., Porter, D. L., O’Holleran, T. P., Hayes, S. L. \& Kennedy, J. R. Lanthanides in metallic nuclear fuels: Their behavior and methods for their control. J. Nucl. Mater. 419(1-3), 263-271, https://doi.org/10.1016/j.jnucmat.2011.08.036 (2011).

7. Hofman, G. L., Walters, L. C. \& Bauer, T. H. Metallic fast reactor fuels. Progress in Nucl. Energy 31(1), 83-110 (1997).

8. Keiser, D. D. \& Cole, J. I. An evaluation of potential liner materials for eliminating FCCI in irradiated metallic nuclear fuel elements. Proc. of GLOBAL 2007, 569-604 (Sep 2007).

9. Khatkhatagy, F. et al. Diffusion barrier properties of nitride-based coatings on fuel cladding. J. Alloys Compds. 580, 442-448, https:// doi.org/10.1016/j.jallcom.2013.06.108 (2013).

10. Benson, M. T., He, L., King, J. A. \& Mariani, R. D. Microstructural characterization of annealed U-12Zr-4Pd and U-12Zr-4Pd5Ln: Investigating Pd as a metallic fuel additive. J. Nucl. Mater. 502, 106-112, https://doi.org/10.1016/j.jnucmat.2018.02.012 (2018).

11. Benson, M. T., King, J. A., Mariani, R. D. \& Marshall, M. C. SEM characterization of two advanced fuel alloys: U-10Zr-4.3Sn and U-10Zr-4.3Sn-4.7Ln. J. Nucl. Mater. 494, 334-341, https://doi.org/10.1016/j.jnucmat.2017.07.057 (2017).

12. Xie, Y., Benson, M. T., King, J. A., Mariani, R. D. \& Zhang, J. Characterization of U-Zr fuel with alloying additive Sb for immobilizing fission product lanthanides. J. Nucl. Mater. 498, 332-340, https://doi.org/10.1016/j.jnucmat.2017.10.039 (2018).

13. Kim, Y. S., Wieneck, T., O’Hare, E. \& Fortner, J. Effectiveness of a dopant in U-Zr metallic fuel to prevent lanthanide migration. Proc. of GLOBAL 2013, 1118-1125 (Sep. 2013).

14. Benson, M. T. et al. Characterization of U-10Zr-2Sn-2Sb and U-10Zr-2Sn-2Sb-4Ln to assess $\mathrm{Sn}+\mathrm{Sb}$ as a mixed additive system to bind lanthanides. J. Nucl. Mater. 510, 210-218, https://doi.org/10.1016/j.jnucmat.2018.08.017 (2018).

15. Kim, Y. S. et al. Effect of indium addition in U-Zr metallic fuel on lanthanide migration. J. Nucl. Mater. 484, 297-306, https://doi. org/10.1016/j.jnucmat.2016.11.012 (2017).

16. Khanal, R. et al. A novel approach to selection of dopant to immobilize neodymium in uranium-based metallic fuels. J. Nucl. Mater., under review (2019).

17. Xie, Y., Zhang, J., Benson, M. T., King, J. A. \& Mariani, R. D. Assessment of Te as a U-Zr fuel additive to mitigate fuel-cladding chemical interactions. J. Nucl. Mater. 513, 175-184, https://doi.org/10.1016/j.jnucmat.2018.10.050 (2019).

18. Janney, D. \& Hayes, S. Experimentally known properties of U-10Zr alloys: A critical review. Nucl. Tech. 203(2), 109-128, https://doi. org/10.1080/00295450.2018.1435137 (2018).

19. Zhang, Y. et al. Microstructural investigation of as-cast uranium rich U-Zr alloys. J. Nucl. Mater. 471, 59-64, https://doi. org/10.1016/j.jnucmat.2016.01.005 (2016).

20. Leibowitz, L., Blomquist, R. A. \& Pelton, A. D. Thermodynamics of the uranium-zirconium system. J. Nucl. Mater. 167, 76-81, https://doi.org/10.1016/0022-3115(89)90426-1 (1989).

21. Xiong, W., Xie, W., Shen, C. \& Morgan, D. Thermodynamic modeling of the U-Zr system - A revisit. J. Nucl. Mater. 443(1-3), 331-341, https://doi.org/10.1016/j.jnucmat.2013.07.034 (2013).

22. Moore, A. P., Beeler, B., Deo, C., Baskes, M. I. \& Okuniewski, M. A. Atomistic modeling of high temperature uranium-zirconium alloy structure and thermodynamics. J. Nucl. Mater. 467, 802-819, https://doi.org/10.1016/j.jnucmat.2015.10.016 (2015).

23. McKeown, J. T. et al. Coexistence of the $\alpha$ and $\delta$ phases in an as-cast uranium-rich U-Zr alloy. J. Nucl. Mater. 436(1-3), 100-104, https://doi.org/10.1016/j.jnucmat.2013.01.313 (2013).

24. Irukuvarghula, S., Ahn, S. \& McDeavitt, S. M. Decomposition of the $\gamma$ phase in as-cast and quenched U-Zr alloy. J. Nucl. Mater. 473, 206-217, https://doi.org/10.1016/j.jnucmat.2016.02.028 (2016).

25. Okamoto, H. Te-Zr (tellurium-zirconium). J. Phase Equilib. 20, 168 (1999).

26. Örlygsson, G. \& Harbrecht, B. Synthesis and crystal structure of $\mathrm{Zr}_{2} \mathrm{Te}$. Distinctions in bonding to isotypic $\mathrm{Sc}_{2} \mathrm{Te}$ and the relationship to the structure of congeneric $\mathrm{Hf}_{2} \mathrm{Te}$ and $\mathrm{Zr}_{2} \mathrm{Se}$. Inorg. Chem. 38(14), 3377-3383, https://doi.org/10.1021/ic990024a (1999).

27. Janney, D. E. \& O'Holleran, T. P. Zr inclusion in actinide-Zr alloys: New data and ideas about how they form. J. Nucl. Mater. 460, 13-15, https://doi.org/10.1016/j.jnucmat.2015.01.065 (2015).

28. Okamoto, H. Nd-Te (neodymium-tellurium). Binary Alloy Phase Diagram, $2^{\text {nd }}$ Ed., Ed. Massalski, T. B. (1990).

29. Kresse, G. \& Furthmüller, J. Efficient iterative schemes for ab initio total-energy calculations using a plane-wave basis set. Phys. Rev. B, 54(16), 11169-11186, https://doi.org/10.1103/PhysRevB.54.11169 (October 1996).

30. Kresse, G. \& Furthmüller, J. Efficiency of ab-initio total energy calculations for metals and semiconductors using a plane-wave basis set. Comput. Mater. Sci. 6(1), 15-50, https://doi.org/10.1016/0927-0256(96)00008-0 (July 1996).

31. Eeles, W. T. \& Sutton, A. L. X-ray determination of the atomic positions in $\alpha$-uranium at $22^{\circ} \mathrm{C}$ and $600^{\circ} \mathrm{C}$. Acta. Cryst. 16(6), 575 , https://doi.org/10.1107/S0365110X63001511 (June 1963).

32. Shields, A. E., Ruiz Hernandez, S. E. \& de Leeuw, N. H. Theoretical analysis of uranium-doped thorium dioxide: Introduction of a thoria force field with explicit polarization. AIP Adv. 5(8), 087118, https://doi.org/10.1063/1.4928438 (August 2015).

33. Chao, J. First-principles study of ternary bcc alloys using special quasi-random structures. Acta Mater. 57(16), 4716-4726, https:// doi.org/10.1016/j.actamat.2009.06.026 (September 2009)

34. Senkov, O. N., Wilks, G. B., Miracle, D. B., Chuang, C. P. \& Liaw, P. K. Refractory high-entropy alloys. Intermetallics, 18(9), 1758-1765, https://doi.org/10.1016/j.intermet.2010.05.014 (September 2010).

35. Singh, S., Wanderka, N., Murty, B. S., Glatzel, U. \& Banhart, J. Decomposition in multi-component AlCoCrCuFeNi high-entropy alloy. Acta Mater. 59(1), 182-190, https://doi.org/10.1016/j.actamat.2010.09.023 (January 2011).

36. Desgranges, L., Baldinozzi, G., Rousseau, G., Nièpce, J. C. \& Calvarin, G. Neutron diffraction study of the in-situ oxidation of UO . $_{2}$ Inorg. Chem. 48(16), 7585-7592, https://doi.org/10.1021/ic9000889 (July 2009).

37. Harbrecht, B. \& Leersch, R. Synthesis and crystal structure of $\mathrm{Zr}_{3}$ Te. J. Alloys Compd., 238(1-2), 13-17, https://doi.org/10.1016/09258388(95)02078-0 (May 1996).

38. Lin, W., Steinfink, H. \& Weiss, E. J. The phase equilibria and crystal chemistry of the rare earth group VI systems. III. neodymiumtellurium. Inorg. Chem. 4(6), 877-881, https://doi.org/10.1021/ic50028a024 (June 1965).

39. Artini, C., Pani, M., Plaisier, J. R. \& Costa, G. A. Structural study of Nd oxidation by means of in-situ synchrotron X-ray diffraction $\left(400 \leq \mathrm{T} \leq 700^{\circ} \mathrm{C}\right)$. Solid State Ionics, 257, 38-41, https://doi.org/10.1016/j.ssi.2014.01.034 (April 2014).

40. Swanson, H. E. \& Tatge, E. Standard X-ray diffraction powder patterns. Natl. Bur. Stand. (U.S.) Circ. 539 , I: 33 (June 1953).

41. Batsanov, S. S., Bokarev, V. P. \& Dorogova, G. V. Shock synthesis of solid solutions of neodymium and samarium chalcogenides. Russ. J. Inorg. Chem. 30(138-139), 246-248 (1985). 
42. Herrmannsdörfer, T., Fischer, P., Mattenberger, K. \& Vogt, O. Temperature dependences of rhombohedral lattice distortion and of ferromagnetic uranium ordering in the uranium monochalcogenides. J. Alloys Compd. 414(1-2), 14-19, https://doi.org/10.1016/j. jallcom.2005.07.022 (2006).

43. de Boer, R., Cordfunke, E. H. P., van Vlaanderen, P., Ijdo, D. J. W. \& Plaisier, J. R. The crystal stuctures of $\mathrm{Zr}_{5} \mathrm{Te}_{4}$ and $\mathrm{Zr}_{3}$ Te. J. Solid State Chem. 139, 213-219 (1998).

\section{Acknowledgements}

Funding to support this research was provided by the Department of Energy's Nuclear Energy University Program (NEUP) grant under contract number DE-NE0008557. Furthermore, the authors gratefully acknowledge the Department of Energy, under DOE-NE Idaho Operations Office Contract DE-AC07-05ID14517. The support from staff was instrumental at both Idaho National Laboratory (INL) and the Center for Advanced Energy Studies (CAES), where much of the research activities were performed. In particular, the Advanced Materials Laboratory (AML) and Microscopy and Characterization Suite (MaCS) located at CAES were used extensively for their radiological sample handling and sample preparation capabilities, as well as for their microscopy and data analysis tools. The authors would like to thank Wayne Poole of INL, as well as Kristi Moser-McIntire, Mason Jaussi, and Joanna Taylor of CAES for their support in the logistics of shipping and handling of the radiological materials. A special thank is conveyed to Bryan Forsmann of CAES for his hands-on support in the radiological work. The computational part of the research made use of the resources at the High Performance Computing Center of INL, which is supported by the Office of Nuclear Energy of the US DOE under Contract DE-AC0705ID14517. Computational power for this study was provided by the High-Performance Computing (HPC) Center at INL. Publication of this article was funded by the University of Idaho - Open Access Publishing Fund.

\section{Author contributions}

M.B. is a researcher and collaborator who performed the arc-melting and casting activities to create the various alloys. J.K. provided guidance on polishing activities. R.M. is a collaborator on the project providing guidance on past research conducted using additives along with M.B. N.J. is a Ph.D. student who performed the polishing of samples. SEM, XRD data analysis and subsequent data collection and data interpretation was performed by N.J; FIB activities and TEM specimen preparation was performed by M.D.; J.B., and N.J. TEM operation and subsequent gathering of data was performed by E.P. and N.J. TEM data interpretation was performed by N.J. with guidance by E.P. I.C. is the university professor and principal investigator on the project overseeing the experimental work. R.K. is a post-doctoral fellow who performed the DFT calculations and analysis. S.C. is the university professor and co-investigator overseeing the computational work on the project. N.J. wrote the manuscript with co-authors providing review and comments.

\section{Competing interests}

The authors declare no competing interests.

\section{Additional information}

Correspondence and requests for materials should be addressed to I.C.

Reprints and permissions information is available at www.nature.com/reprints.

Publisher's note Springer Nature remains neutral with regard to jurisdictional claims in published maps and institutional affiliations.

(c) (i) Open Access This article is licensed under a Creative Commons Attribution 4.0 International License, which permits use, sharing, adaptation, distribution and reproduction in any medium or format, as long as you give appropriate credit to the original author(s) and the source, provide a link to the Creative Commons license, and indicate if changes were made. The images or other third party material in this article are included in the article's Creative Commons license, unless indicated otherwise in a credit line to the material. If material is not included in the article's Creative Commons license and your intended use is not permitted by statutory regulation or exceeds the permitted use, you will need to obtain permission directly from the copyright holder. To view a copy of this license, visit http://creativecommons.org/licenses/by/4.0/.

(C) The Author(s) 2019 